\title{
JUROR STIGMA TOWARDS MENTAL ILLNESS AND THE EFFECTS OF \\ CHALLENGE FOR CAUSE PROCEDURES
}

\author{
by \\ Annik Mossière \\ A thesis submitted to \\ the Faculty of Graduate and Postdoctoral Affairs \\ in partial fulfillment of the requirements for the degree of: \\ Master of Arts \\ in \\ Psychology \\ Carleton University \\ Ottawa, Ontario \\ (C) 2012 Annik Mossière
}


Library and Archives

Canada

Published Heritage

Branch

395 Wellington Street

Ottawa ON K1A ON4

Canada
Bibliothèque et

Archives Canada

Direction du

Patrimoine de l'édition

395 , rue Wellington

Ottawa ON K1A ON4

Canada
Your file Votre référence

ISBN: 978-0-494-93606-1

Our file Notre référence

ISBN: 978-0-494-93606-1
NOTICE:

The author has granted a nonexclusive license allowing Library and Archives Canada to reproduce, publish, archive, preserve, conserve, communicate to the public by telecommunication or on the Internet, loan, distrbute and sell theses worldwide, for commercial or noncommercial purposes, in microform, paper, electronic and/or any other formats.

The author retains copyright ownership and moral rights in this thesis. Neither the thesis nor substantial extracts from it may be printed or otherwise reproduced without the author's permission.
AVIS:

L'auteur a accordé une licence non exclusive permettant à la Bibliothèque et Archives Canada de reproduire, publier, archiver, sauvegarder, conserver, transmettre au public par télécommunication ou par l'Internet, prêter, distribuer et vendre des thèses partout dans le monde, à des fins commerciales ou autres, sur support microforme, papier, électronique et/ou autres formats.

L'auteur conserve la propriété du droit d'auteur et des droits moraux qui protege cette thèse. $\mathrm{Ni}$ la thèse ni des extraits substantiels de celle-ci ne doivent être imprimés ou autrement reproduits sans son autorisation.
In compliance with the Canadian Privacy Act some supporting forms may have been removed from this thesis.

While these forms may be included in the document page count, their removal does not represent any loss of content from the thesis.
Conformément à la loi canadienne sur la protection de la vie privée, quelques formulaires secondaires ont été enlevés de cette thèse.

Bien que ces formulaires aient inclus dans la pagination, il n'y aura aucun contenu manquant. 


\begin{abstract}
Objective: This study explored juror stigma towards mentally ill defendants, and examined the impact of a new challenge for cause procedure in decision-making. Method: Participants' attitudes towards mental illness (MI) were assessed. Participants were randomly assigned to a challenge for cause procedure and were provided with a trial transcript, in which the MI of the defendant was manipulated. Participants made a judgement about the defendant's guilt, and sentencing if applicable. Finally, a post-test of attitudes towards MI was completed. Results: Limited relationships were found between the variables. Neither MI nor challenge type had a significant effect on juror decisions. There were no differences between pre and post attitude scores regardless of challenge type.

Discussion: Findings suggest that questions about court proceedings in cases involving a defendant with a MI may need to be framed differently. Attitudes towards mentally ill offenders may need to be explored using more ecologically valid methods.
\end{abstract}




\section{Acknowledgments}

First and foremost, I would like to thank my supervisor, Dr. Evelyn Maeder. She took a chance on me when no one else would, and for which I am forever grateful. Evelyn's mentorship, support, and knowledge were indispensable throughout this research project. I would also like to express my sincere gratitude to my committee for their time, expertise, and thoughtful insights - Dr. Craig Bennell, Dr. Diana Majury, and Dr. Joanna Pozzulo. This document is stronger thanks to them. To my Carleton peers who became my Ottawa family Amy, Norway, Janelle, and Adam - thank you for your countless hours of encouragement, motivation, and laughter.

I would like to dedicate this thesis to my grandmother, Marketa Newman, an exceptionally strong and inspiring woman who overcame great life obstacles and always recognized the importance of education. She is my hero, and would be so proud of this thesis if she were here today. I would like to thank my Zlata Mama and Seeester for their unconditional support and love - you both have offered me endless positivity and patience which have kept my academic goals alive. Thank you also to Papa Gilles, the only other Newman/Mossière who can really understand and appreciate the pursuit of a Master's degree. 


\section{Table of Contents}

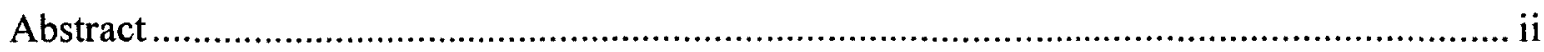

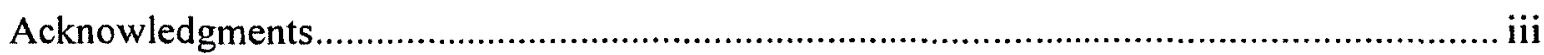

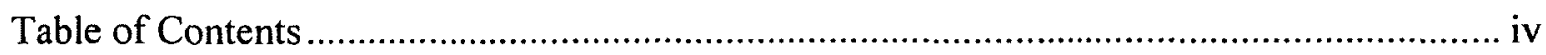

Juror Stigma towards Mental Illness and the Effects of Challenge for Cause Procedures...... 1

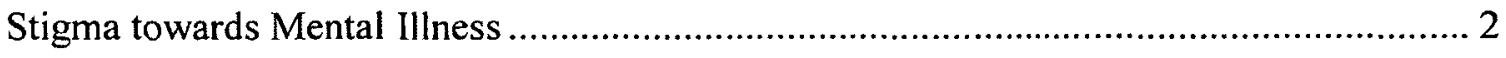

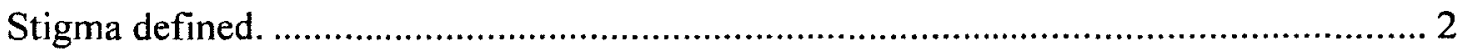

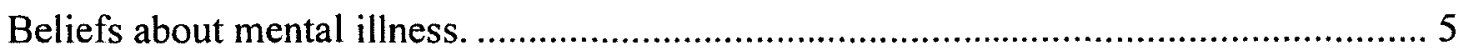

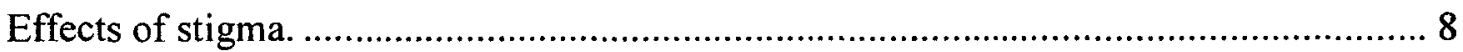

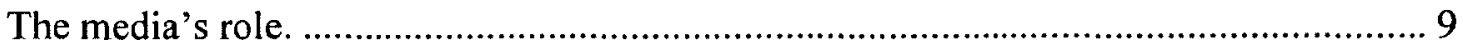

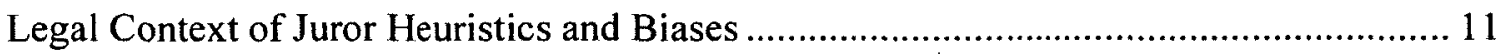

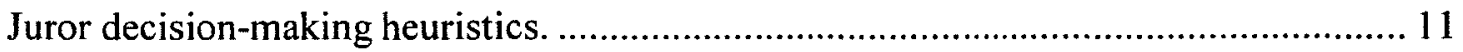

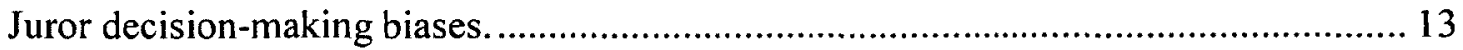

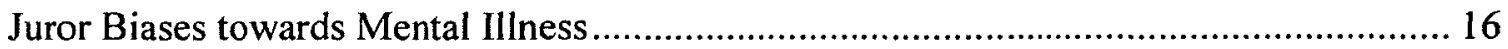

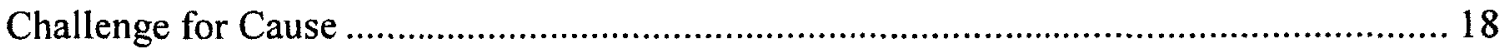

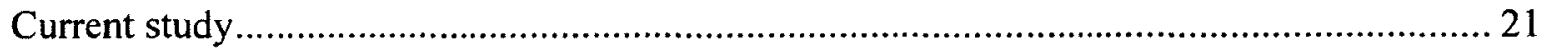

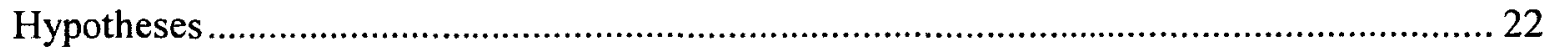

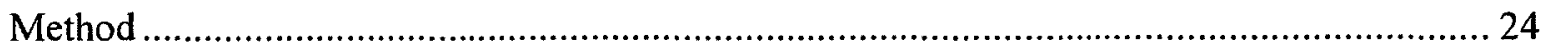

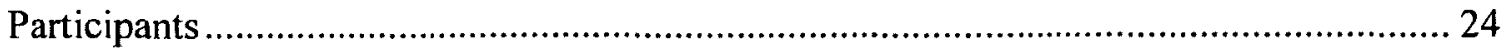

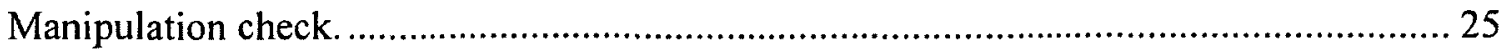

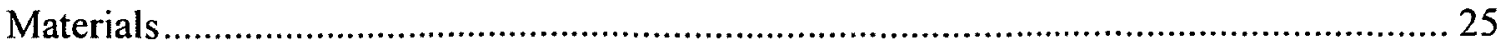


Procedure.

Design

Results

Table 1. Failed Manipulation Checks per Mental Illness and Challenge Condition ..... 30

Table 2. Relationship of Variables as Demonstrated by Correlation Analyses

Dichotomous Verdict and Sentencing Decisions

Continuous Ratings

Continuous verdict.

Figure 1. Mean Continuous Verdict Across Mental Illness Conditions

Figure 2. Mean Continuous Verdict Across Challenge for Cause Procedures

Sentence length.

Figure 3. Mean Sentence Length in Years Across Mental Illness Conditions

Figure 4. Mean Sentence Length in Years Across Challenge for Cause Procedures .... 35

Defendant likability.

Figure 5. Mean Impressions of the Defendant Across Mental Illness Conditions 36

Figure 6. Mean Impressions of the Defendant Across Challenge for Cause Procedures

Effect of Stigma on Trial Decisions

Influence of Challenge Procedures on Pre-Post Attitudes

Discussion 
Conclusion. 48

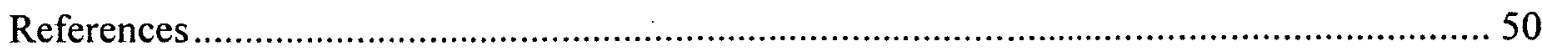

APPENDIX A: EXAMPLE of SONA RECRUITMENT NOTICE .............................. 63

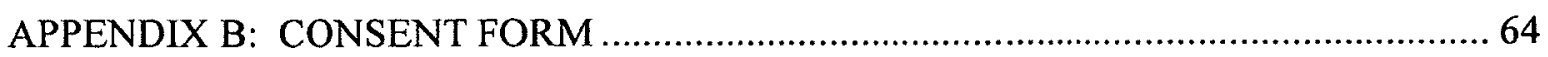

APPENDIX C: ATTITUDES AND FILLERS QUESTIONNAIRE ...............................68

APPENDIX D: JUROR PRE-TRIAL/CHALLENGE QUESTIONS ............................ 77

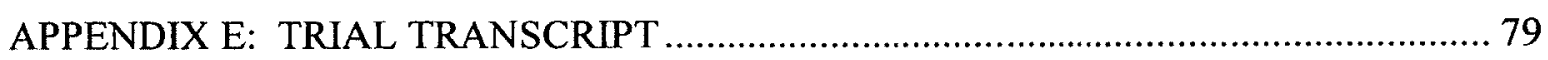

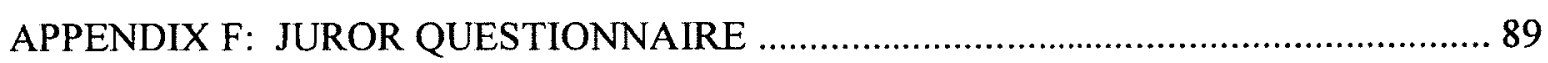

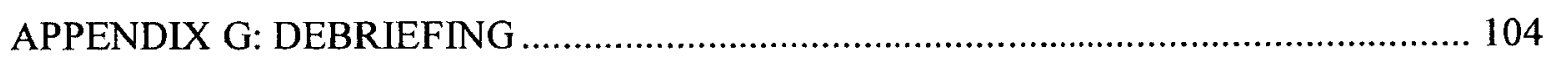




\section{Juror Stigma towards Mental Illness and the Effects of Challenge for Cause Procedures}

Stigma towards mental illness is very real and, unfortunately, much too common (Rüsch, Angermeyer \& Corrigan, 2005). It can be defined as pejorative beliefs and attitudes towards mental illness, which may result in prejudice and discrimination towards individuals with mental illness (Link \& Phelan, 2001). Many initiatives have been introduced to combat this issue; however more work needs to be done, and steps must be taken to address and reduce eliminate stigma towards mental illness. One area in which stigma towards mental illness needs to urgently be addressed is in law and corrections. The number of people with mental disorders in Canadian prisons and jails is higher than ever, and it continues to rise. Currently, it is estimated that $15-30 \%$ of inmates have a mental illness, and that most were recognized or diagnosed prior to conviction (Koskie, Hendrick, \& Kelly, 2010; CSC, 2008). In Canada, some might say that we are criminalizing mental illness by incarcerating many individuals with diagnosed disorders, and that prisons can be dangerous and destructive places for people with mental illness (Koskie et al., 2010). Some attention is being given to rehabilitation initiatives in prisons and upon release into the community; however, little research to date has dealt with the matter of stigma in the courtroom during trial proceedings, before individuals with mental illness can become inmates.

The Not Criminally Responsible by Account of Mental Disorder (NCRMD) defence in Canada is sometimes applied in cases involving mental illness. The NCRMD defence is used when a mental disorder rendered the person incapable of appreciating the nature and quality of the act or of knowing that it was wrong. NCRMD is not relevant, however, in cases where this defence would not hold - those cases in which the mental illness is not being considered with respect to the culpability of the defendant (i.e., where the defendant 
happens to have a mental illness but is still capable of appreciating the nature of the act). It is essential to distinguish a guilty verdict based on the evidence provided in court, versus a biased verdict based on stigma. Importantly, juror stigma has the daunting potential to lead to the wrongful conviction of an innocent person just because he or she may have a mental illness. This in itself is Human Rights abuse, and it is driven by a stereotype of dangerousness and the concomitant response of fear. The aim of the current study was to explore the issue of juror stigma towards criminal defendants with mental illness.

\section{Stigma towards Mental Illness}

Stigma defined. The concept of stigma has been examined for several decades; however, it has gained increasing attention and interest in the past 10 years (Mak, Poon, Pun, \& Cheung, 2007). Stigma was first defined as a spoiled identity that discredits a person in society (Goffman, 1963). The process of stigma can be further explained by its three inextricably linked components: stereotypes, prejudice, and discrimination (see Corrigan \& Watson, 2002; Eagly \& Chaiken, 1998; Petty \& Wegener, 1998). Stereotypes are the cognitive component - the mental structures representing collectively shared beliefs about a select group of people. Prejudice is the affective component - if stereotypes are adopted, these result in negative emotions about that group. Discrimination is the behavioural component - prejudices are acted upon and biased behaviour develops towards the stigmatized group.

Given that attitudes have been shown to predict behaviours, the importance of stigma is emphasized (Maio, Olson, Bernard, \& Luke, 2003). Attitudes lay the foundation for stigma to occur as they are evaluative (reflect positivity or negativity towards a group), subjective (reflect how a person sees the world), and exist at conscious and unconscious levels (Maio et al., 2003). The three-component model of attitudes highlights that attitudes 
express feelings, beliefs, and past behaviours regarding a group (Zanna \& Rempel, 1988).

Correspondingly, individuals with positive attitudes towards a group often possess

favourable beliefs, feelings, and behaviours towards that group. There are various factors

that increase the likelihood that attitudes will predict behaviour and consequently

stigmatization. Cognitive closure (Kruglanski \& Freund, 1983) and cognitive overload

(Macrae, Hewstone, \& Griffiths, 1993) are such methods that can influence behaviour and

encourage the use of stereotypes. Cognitive closure occurs in complex thought processing.

This refers to when a person's mind freezes the search for more information, and this in turn favours the use of preconceptions such as stereotypes (Kruglanski \& Freund, 1983). Urgent situations and tendencies towards permanence encourage the need for cognitive closure. In the same way, Macrae et al. (1993) suggest that the relative automaticity of stereotypes is functional and saves cognitive resources, particularly in times of cognitive overload.

Context is another factor that leads attitudes to be predictive of behaviour. Allport (1954) analyzed prejudice, and developed the idea that the social categorization of people [as either in-group or out-group, or $u s$ vs. them] is driven by social context. In following, stigma (a.k.a. stereotyping, prejudice, \& discrimination) is driven by social structure assuming fundamental processes of categorization and other cognitive economies (Fiske, 1998). Categorization and cognitive economies are based on positive or negative social reinforcements for cognitive processes, such as stereotype-confirming or stereotypecontradictory information (Rothbart, 1981). Behaviour is also more likely to be predicted by attitudes when illusory correlations take place (Hamilton \& Gifford, 1976). This process refers to an erroneous inference about the relationship between two categories of events, such as people overestimating the frequency that out-group members act stereotypically (Hamilton \& Gifford, 1976). This concept has been further examined in terms of the 
accessibility of stereotypes in information processing, with the identification of expectancyconfirming and accuracy-oriented processing goals (Stangor, 1988; Stangor \& Ford, 1992).

Link and Phelan (2001) have thoroughly investigated the development of stigma as a whole, and similarly state that this process starts off by recognizing and labelling a difference between a person and other people. This idea stems from Gordon Allport's previously mentioned identification of social categorization (Allport, 1954) and from Howard Becker's early work on labelling theory (Becker, 1963). Generally speaking, Becker explains labelling theory through the view that deviance is the creation of social groups and not the quality of some act or behaviour. According to labelling theory, studying the act of the individual is unimportant because deviance is merely rule breaking behaviour that is labeled deviant by persons in positions of power. In other words, social groups create deviance by making rules [whose infractions constitutes deviance], and apply those rules to particular people, labelling them as outsiders (Becker, 1963). Link and Phelan (2001) continue this by explaining that the labelled person is thereby linked with society's dominant negative stereotypes about this group. As a result, this disassociation, separating the "other" from society, exposes this person to discrimination and negative social consequences.

Link and Phelan identify three types of discrimination: (1) Individual discrimination is usually expressed in the form of social distance, where laypeople would rather keep the other at a distance (i.e. not in their neighbourhood); (2) Structural discrimination describes the negative consequences that occur as a result of the injustice in social and political structures that surround the stigmatized group; and in contrast, (3) Self-stigmatization comes from within the stigmatized person him or herself, where he or she internalizes the stigma responses and adopts society's stereotypes about that group (Link \& Phelan, 2001; Mak et al., 2007). In terms of stigma towards mental illness, this can be defined as pejorative beliefs and attitudes towards mental illness, which is seen as a detrimental trait that shames a 
person, and may result in prejudice and discrimination towards that person with mental illness (Link \& Phelan, 2001). Evidence of separating us from them is apparent in the very nature of the labels used in society. For example, society tends to speak of persons as being "schizophrenic" or "depressed" as opposed to describing them as having, or living with, schizophrenia or depression. Link and Phelan (2001) suggest that when people are labelled, set apart, or linked to undesirable characteristics, a justification is constructed for devaluing, rejecting, or excluding them.

Beliefs about mental illness. In a review of 62 population studies, Angermeyer and Dietrich (2006) found that, in general, members of the public have skewed views and cannot correctly recognize mental disorders. Specifically, schizophrenic symptoms are considered to be signs of mental illness more often than are symptoms of depression or of alcoholism. This review also highlighted that laypeople do not know much about the causes of mental illness, i.e., psychosocial factors as a primary cause over biological factors (Angermeyer \& Dietrich, 2006). Notably, although the majority of the public in these studies consider people with mental disorders as in need of help, a substantial portion of the public perceive these individuals as unpredictable and dangerous. The public primarily worries about violence that is random, irrational, and unpredictable, and they tend to associate this with mental illness (Stuart, 2003). In following, a great deal of the public reacts to mental disorders with fear and tends to keep a distance from those who have them (Angermeyer \& Dietrich, 2006).

Research suggests that stereotypes of dangerousness associated with mental illness are on the rise, yet studies show that only a minority of people with mental illnesses are in fact violent (Link, Phelan, Bresnahan, Stueve, \& Pescosolido, 1999). Monahan's research (1984, 1988) acknowledges the debate surrounding the link between violence and mental illness. While recognizing that the belief that people with mental illness are violent has been 
a foundational concern in mental health law for a long time, Monahan had concluded that 1) the best predictors of violence among the mentally ill are in fact the same demographic factors that are the best predictors of violence among non-disordered offender populations, and that 2) the diagnosis or severity of disorder, or personality traits are the poorest predictors of violence among the mentally ill (Monahan, 1984,1988). Monahan $(1988,2002)$ suggests that not only have these conclusions been challenged by much research (see Binder \& McNeil, 1988; Klassen \& O'Connor, 1988a) but that research surrounding this issue is inconsistent. This ongoing debate highlights the need for additional research examining the link between the violence and mental illness.

Research by Pescosolido, Monahan, Link, Stueve, and Kikuzawa (1999) found that, after controlling for the type of mental health problem and its severity, participants reported less competence and increased expectations of violence if the person in the vignette was labelled as having a mental illness. That being said, there are often marked differences in the public's concerns, beliefs, and attitudes: people with psychoses, schizophrenia, drug addiction, or alcoholism are considered unpredictable and violent more often than are people with depression and anxiety disorders (Angermeyer, Buyantugs, Kenzine, \& Matschinger, 2004; Angermeyer \& Dietrich, 2006; Corrigan; River, Lundin, Wasowski, Campion, Mathisen, Goldstein, Bergman, \& Gagnon, 2000; Crisp, Gelder, Rix, Meltzer, \& Rowlands, 2000; Schomerus, Holzinger, Matschinger, Lucht, \& Angermeyer, 2010). Pescosolido et al. (1999) suggest that the public's perceived link between mental illness and violence is central to stigma and discrimination, and that people are more likely to condone forced legal action and coerced treatment when dealing with issues involving violence. A study by Link, Cullen, Frank, and Wozniak (1987) explored the stereotypic effects of labelling mental illness. This study experimentally manipulated labelling, with a random half of vignettes as "former mental patients" and the other half as "former back-pain patients". A measure of 
perceived dangerousness about mental patients was also included. It was found that the "former mental patient" label elicited a negative response from participants who believed mental patients were dangerous. The label of mental illness is unconsciously linked to stereotyped beliefs about the dangerousness of people with mental illness, which in turn leads to a desire of social distance from that person (Link \& Phelan, 2001).

On an encouraging note, Angermeyer and Dietrich (2006) observed a positive association between familiarity with mental illness and the acceptance of people with mental disorders. This suggests that interactions with individuals who have mental illnesses may aid in breaking down stigma and stereotypes (Corrigan et al., 2000; Phelan \& Link, 2004). This finding seems contradictory given the overwhelming association of mental illness with dangerousness, as one would think that exposure to people with mental illness would make for negative associations and increased stigma. Phelan and Link (2004) try to explain the dangerousness connection in terms of indirect observations via the media, which will be explained in more detail shortly.

Fiske (2011) suggests that there are multiple types of stigma towards different mental illnesses. Those with schizophrenia are stereotyped as "disgusting and scary", those with bipolar disorder or depression are labelled "geniuses", while those with attention deficit disorder or eating disorders are considered "normal" (Fiske, 2011). Interestingly, several mental illnesses such as psychosis, depression, anxiety, and substance-related disorders are over-represented in Canada's correctional facilities (Canadian Institute for Health Information, 2008; Folsom 2009). Although specific prevalence numbers are not yet identified in Corrections Canada for the different disorders, the overall rates are much higher than rates found in the community (e.g. total of $0.5 \%$ of men in the community are diagnosed with a major mental illness compared to $8 \%$ in federal prison, and $7 \%$ are diagnosed with depression compared to the $22 \%$ found in prison) (Folsom, 2009). Drawing 
from this and the previous research noted above, the current study explored the issue of stigma, and investigated the differences in stigma towards multiple levels of mental illness, by using three mental illness groups relevant to those found in corrections. Using No Mental Illness as a control, this study used one group which represented the stereotypically violent category (schizophrenia), and two which represented the non-violent category (obsessive compulsive/anxiety and depression). These three mental illnesses are classified as Axis I psychiatric disorders in the Diagnostic and Statistical Manual of Mental Disorders $\left(4^{\text {th }} \mathrm{ed}\right.$, American Psychiatric Association, 2000). There are various sub-classifications of these mental illnesses, but generally speaking, schizophrenia is a psychotic disorder typically characterized by delusions, hallucinations, and disorganized behavior or speech. Depression (Major Depressive Disorder) is a mood disorder characterized by a number of symptoms including feelings of sadness or emptiness, reduced interest in routine activities, sleep disturbances, and suicidal thoughts. Obsessive compulsive disorder in an anxiety disorder involving persistent and uncontrollable thoughts, and actions/behaviors used to address these obsessions that are severe to the point of disturbing normal everyday functioning. Anxiety and depression are often comorbid with each other. Both depression and OCD are very common in schizophrenia as well, with rates of $50 \%$ and $23 \%$ respectively (Buckley, Miller, Lehrer, Castle, 2009). All three mental illnesses have high co-occurrence rates with substance (alcohol and/or drug) abuse, although the directionality of the relationships varies (substance abuse can cause/trigger a mental illness, mental illness can cause or lead to substance abuse, or both are caused by another common risk factor).

Effects of stigma. Among the many negative opinions of people with mental illness, perceptions of danger are especially detrimental to the well-being of people with mental illness (Link et al., 1999; Phelan \& Link, 2004). Stigma towards mental illness can also be a barrier to those in need of treatment and can greatly limit opportunities (Corrigan et al., 
2000; Kobau, Dilorio, Chapman, \& Delvecchio, 2010). Individuals with mental illnesses are directly affected by the stigma that society holds towards them. This is evident in many areas: employers are less likely to hire someone labelled mentally ill, individuals with mental illness are less likely to be accepted for a lease on an apartment, and mentally ill persons are more likely to have charges pressed against them for violent crimes (Corrigan et al., 2000; Phelan \& Link, 2004).

Discrimination involves a lowered status that might also make a person with mental illness less attractive to socialize with or to include in community activities or business ventures (Link \& Phelan, 2001). Furthermore, stigma can be damaging in terms of seeking help or treatment for their illness. Individuals who have a mental illness may be reluctant to seek professional help for fear of stigmatization (Link et al., 1999). According to labelling theory modified to mental disorders, the more patients believe that they will be devalued and discriminated against, the more they feel threatened by interacting with others (Link, Cullen, Struening, Shrout, \& Dohrenwend, 1989). In following, they may keep their treatment a secret, try to educate others about their situation, or withdraw from social contacts that they perceive as potentially rejecting. Link and colleagues (1989) suggest that such strategies can lead to overall negative consequences for social support networks, jobs, and self-esteem. Moreover, stigma towards mental illness impedes therapy rehabilitation efforts and reintegration of offenders into society. The potential for reducing stigma towards mental illness in a correctional setting is important as forensic research demonstrates that one of the main protective factors in desistance (the process wherein offenders cease criminal behaviour) is a sense of identity and self-efficacy, which is assured by the absence of stigma (Felson, 1985; Lebel, Burnette, Maruna, \& Bushway, 2008; Serin, Lloyd, \& Hanby, 2010).

The media's role. The media may be the public's primary, and therefore most important, source of information about mental illness. That being said, the media often 
provide an inaccurate image of people with mental illness. In an overview of international studies on the portrayal of mental health and illness in the media, Francis, Pirkis, Dunt, and Blood (2001) drew this conclusion by stating that mental illness is portrayed pejoratively, as the media promote negative images and stereotypes. In addition, there is a strong link between mental illness and violence in media messages, and stories associating mental illness with violence and crime are given greater prominence than positive items about mental illness (Francis et al., 2001). Instead of covering stories about people overcoming mental illness or accomplishments in recovery, the media sensationalize rare, tragic events associated with someone having a mental disorder, thereby amplifying the public's fear towards people with mental illness, and reinforcing the "dangerous" stereotype (Kobau et al., 2010).

A study by Dietrich, Heider, Matschinger, and Angermeyer (2006) explored the influence of newspaper reporting on adolescents' attitudes towards people with mental illness. Findings from this study are consistent with previous research, whereby participants who read an article linking mentally ill persons with violent crime were significantly more likely to describe a mentally ill person as violent or dangerous (Dietrich et al., 2006). Similar messages are exhibited in television shows. Wilson, Nairn, Coverdale, and Panapa (1999) examined how the mentally ill are depicted in prime-time television dramas. Findings demonstrate that mentally ill characters were often portrayed as physically violent towards themselves or others. In addition, characters were shown as lacking in comprehension and appearing lost, unpredictable, unproductive, asocial, vulnerable, untrustworthy, and dangerous (Wilson et al., 1999). Phelan and Link (2004) explain that the stories conveyed in the media are reported and framed in a manner that is consistent with societal beliefs and stereotypes, thereby strengthening them. Attitude and behaviour consistency is determined by embeddedness (a.k.a. working knowledge) - where the amount of attitude relevant 
information that is linked to the attitude is predictive of actions (Maio et al., 2003). The media's depiction of mental illness stereotypes makes people's attitudes towards mental illness more prominent and cognitively accessible, thereby making these attitudes better predictors of behaviour (Maio et al., 2003). Likewise, media coverage and television shows of violent actions by a person with a mental illness may increase the cognitive availability, and thus the perceived probability, of such events through heuristics (Phelan \& Link, 2004).

\section{Legal Context of Juror Heuristics and Biases}

Juror decision-making heuristics. Tversky and Kahneman (1973, 1974) developed ground-breaking work suggesting that people rely on a limited number of heuristic principles, which reduce the complex tasks of assessing probabilities and predicting values to simpler judgemental operations. Heuristics can be more simply explained as mental shortcuts that individuals unconsciously use on a daily basis to make judgements quickly and efficiently. Gigerenzer (2008) promotes the idea that heuristics are beneficial as they exploit successfully evolved problem solving. Gigerenzer (2008) suggests that the mind resembles an "adaptive toolbox" with various heuristics customized for specific environments or problems, and that as humans we discover in which environment a given heuristic performs well, and we adapt accordingly. Although adaptive and useful at times, heuristics are complicated processes and do not always guarantee correct solutions to problems (Abel, 2003; Mayer, 1983). Complementary to the work launched in the 1970's, basic principles outlined in Hamilton's book volume (1981) suggest that "all people are cognitive misers, overwhelmed by the complexity of the social environment and forced to conserve scarce mental resources" (as cited in Fiske, p.362, 1998). Tversky and Kahneman (1974) describe two relevant heuristics that are employed in making judgements under situations of complexity or uncertainty: (i) representativeness, which is usually employed 
when people are asked to judge the probability that an individual or event belongs to a group or process; (ii) availability of instances or scenarios, which is often used when people are asked to assess the frequency of a group or the plausibility of a particular development. Although these shortcuts are effective in most circumstances, they can also lead to systematic errors in reasoning, also known as cognitive biasing or stereotyping (Evans, 1984; Tversky \& Kahneman, 1974). In a review of the literature, Link and Phelan (2001) conclude that the activation of stereotypes is automatic, silent, passive, and difficult to control. Although the use of stereotypes is highly functional in the sense of parsimonious information processing about given people (Gigerenzer, 2008), stereotyping may be considered dysfunctional because it hinders individual impression formation (Fiske \& Neuberg, 1990; Gollwitzer \& Schaal, 1998).

Jurors are individuals randomly selected from the community, and as such, they each come into this role with previous life experiences, stores of knowledge, heuristics, and biases. These have the potential to interfere in decision-making, and can lead jurors to form positive or negative stereotypes about a person or group, thereby conceivably influencing their verdicts (Colwell, 2005; Jones, 1997; Louden \& Skeem, 2007; Nikonova \& Ogloff, 2005). Keeping this in mind, according to the Canadian Charter of Rights and Freedoms, all persons are to be "presumed innocent until proven guilty according to law in a fair and public hearing by an independent and an impartial tribunal" (Section 11 of the Charter, 1982). Accordingly, the Canadian Judicial Council identifies an acceptable juror as a person who is fair, which means that he or she will approach jury duty with an open mind and without preconceived ideas. The juror must decide the case solely on the evidence given at trial and the legal instructions given by the trial judge. Jurors are to make their decision without sympathy, prejudice or fear, and should not be influenced by public opinion. Vidmar (1997) identifies four types of prejudice implicit in Canadian cases dealing with juror 
impartiality. The first is interest prejudice, which involves juror bias as a result of their direct/personal interest in the outcome of the case. The second is specific prejudice, which can stem from the mass media, or discussion and rumours in the community. The third is generic prejudice, which involves attitudes, beliefs, and stereotypes about certain groups of people. Finally, the fourth type of prejudice is normative prejudice, referring to jurors being influenced by community sentiment and interest in a particular outcome of the case. Bias stemming from stigma towards the mentally ill would fall under Vidmar's generic prejudice label. If a juror is biased or exhibits prejudice against a particular group to the point that he or she is unable to entertain the defendant's legally established defence, that defendant will not obtain a fair trial.

Juror decision-making biases. The Story Model (Pennington \& Hastie, 1986) is the most advanced and most used theory in juror research (Schuller \& Yarmey, 2001). This theory explains that jurors are likely to select a guilty verdict if the evidence provided in court maps onto a story that, in their minds, makes sense in a coherent whole or narrative story structure about the guilt of the defendant (Pennington \& Hastie, 1986). Individual jurors, however, may draw different interpretations from the same evidence because they base their "stories" on their different personal knowledge and experiences (Schuller \& Yarmey, 2001). As previously mentioned, sometimes these experiences can increase the risk of stereotyping, where jurors can lack the adequate framework for evaluating trial evidence.

Social psychology has long been concerned with the idea that social categories like race, gender, and social class can influence people's interpretation of, and reactions to, ambiguous stimuli. In the domain of criminal justice, category-based judgements can have profound consequences through slow, deliberative decisions like those made by a jury (Eberhardt, Davies, Purdie-Vaughns, \& Johnson, 2006; Sommers \& Ellsworth, 2000). Severe errors in judgement can occur in a legal context when stereotypes overshadow the 
specific facts of a case (Colwell, 2005). Although jurors are instructed to consider only the formally presented evidence in reaching a verdict, jurors can be influenced by many types of extra-legal factors and characteristics (Bornstein \& Rajki, 1994; ForsterLee, ForsterLee, Horowitz \& King, 2006; Mazzella \& Feingold, 1994). These factors can be defendant centered or can also be characteristics of the juror. Research has demonstrated that juror age (e.g. Mossière \& Dalby, 2008); juror religion (e.g. Eisenberg, Garvey, \& Wells, 2001); juror gender (e.g. Guy \& Edens, 2003 \& 2006; McNamara, Vattano, \& Viney, 1993; Pozzulo, Dempsey, Maeder, \& Allen, 2010; Schutte \& Hosch, 1997); juror race (e.g. Bornstein \& Rajki, 1994; Brewer, 2004; Foley \& Chamblin, 1982; Sommers \& Ellsworth, 2001), and juror socioeconomic status (e.g. Bornstein \& Rajki, 1994) all have the potential to influence juror decisions.

Research conducted over the past two decades has also demonstrated that due to defendant source characteristics, many social groups are perceived negatively, and these prejudicial views may play a direct role within the judicial process (Colwell, 2005; Jones, 1997). In continuing with the Story-Model theory, one explanation for these prejudicial views is that such characteristics often covary with criminality, and errors in decisionmaking are especially pertinent when defendants who belong to a particular group are accused of stereotype-consistent crimes. This idea is consistent with the "typicality effect" (Lord, Lepper, \& Mackie, 1984), which hypothesizes that attitudes will predict behaviour towards "typical" members of a group - in other words, will elicit attitude-consistent behaviour (Lord et al., 1984). Colwell (2005) suggests that judges and jurors likely develop stereotypes about what they consider to be "typical criminals," then use those stereotypes to make judgements about a particular defendant in question. Characteristics overrepresented among perpetrators are the likely victims of stereotyping by jurors (Mazzella \& Feingold, 1994). This has been demonstrated with males (e.g., Pozzulo et al., 2010); African 
Americans (e.g., Sommers \& Ellsworth, 2000), the poor (e.g., Mazzella \& Feingold, 1994), and the unattractive (e.g., Mazzella \& Feingold, 1994). Jurors may subconsciously find these types of personal characteristics relevant, and be more likely to assume a defendant is guilty when the defendant possesses characteristics that are more commonly observed in criminals.

Racial bias and bias towards mental illness are different concepts, however as there is little literature on juror bias towards MI, it is of interest to examine and to draw from the research that has demonstrated views of criminality in cases involving race. An early study explored mock jurors' recommended sentences in potentially racially-stereotyped crimes (embezzlement $=$ White and burglary $=$ Black $)$. Findings demonstrated that White embezzlers received longer jail sentences than Black embezzlers, and that Black burglars received longer jail sentences than White burglars (Gordon, Bindrim, McNicholas, \& Walden, 1988). Similarly, Eberhardt and colleagues (2006) examined whether the likelihood of being sentenced to death is influenced by the degree to which Black defendants are perceived to have a stereotypically Black appearance. Controlling for a wide array of factors, this study found that in cases involving a White victim, the more stereotypically Black a defendant is perceived to be, the more likely that person is to be sentenced to death. Jurors are influenced not simply by the knowledge that the defendant is Black, but also by the extent to which the defendant appears stereotypically Black (Eberhardt et al., 2006). The stereotype consistent theory in this case, is rooted in the fact that previous research has already shown that people associate Black physical traits with criminality (Eberhardt, Goff, Purdie, \& Davies, 2004). The 2006 study demonstrates that in actual sentencing decisions, jurors may treat those traits as powerful cues to "deathworthiness" (Eberhardt et al., 2006).

Drawing from the race literature, stereotype-consistent-crime theory was the basis for the present study exploring stigma towards mental illness. For the purpose of this study, take for example a violent crime where two suspects are on trial; one who happens to have a 
mental illness and one who does not. Because of society's stigma towards mental illness, labelling them as unpredictable and dangerous, based on the stereotype consistent theory, a juror may be more likely to give a guilty verdict to a defendant who has a mental illness than to one who does not.

\section{Juror Biases towards Mental Illness}

People with serious mental illness are often charged with more serious crimes than other people arrested for similar behaviours (Tellier \& Felizardo, 2011). Over a nine-year period, there has been a $70 \%$ increase in the number of offenders with psychiatric diagnosis on admission to the correction system (Folsom, 2010). The relevance and importance of dealing with mental illness in a legal context has been recognized in the last decade with the development of Mental Health Courts and the introduction of the NCRMD verdict. The specialized courts involve mental health and legal professionals, and have been set up to accommodate the needs of people with mental illness charged with minor criminal offences. By integrating traditional criminal justice principles and the philosophy of providing treatment and assistance, the primary goal of these courts is to minimize offenders' cyclical contact with the criminal justice system (McGuire, 2000) and the unremitting stigmatization that can be involved. This goal is accomplished by making use of psychiatric, legal and community resources, specifically diversion programs. While the introduction of these courts is significant, unfortunately they are not applicable in cases of persons with mental illness charged with more serious offences. The NCRMD verdict can be used for serious offences; however, as mentioned earlier, an individual charged with a criminal offence who has been found to have a mental illness is not necessarily exempt from criminal responsibility. NCRMD status is based upon strict legal consideration by a judge. The NCRMD verdict is not valid in cases where the mental illness did not render the accused 
unable to appreciate the nature of the crime, and as such, many accused with a mental illness are therefore tried and convicted within the regular criminal justice system (Latimer $\&$ Lawrence, 2006). Even when the accused person is found criminally responsible for the offence; the courts may still consider their mental health condition in sentencing decisions (Sinha, 2009). Canadian data suggests that that the issue of mental disorders is being raised more often in court (Latimer \& Lawrence, 2006), and accordingly, the focus of this present paper was to study the consideration of mental illness in regular court, and to examine its influence on legal outcomes.

Link and Phelan (2001) caution that the amount of stigma experienced by people with mental illness will be shaped by the relative power of the stigmatized and the stigmatizer. Fiske (1993, p. 621) states: "stereotyping and power are mutually reinforcing because stereotyping itself exerts control, maintaining and justifying the status quo". In following then, because power can foster an environment for stigma and discrimination to occur, the courtroom setting (where the jurors have substantial power over the defendant) makes for a potentially vital place for stigma to transpire. Juror bias towards mental illness has not received much attention in the psycho-legal literature.

Rare examples of studies observing prospective prejudice towards mental illness in court can be found in research involving the NCRMD or the Insanity defence. An example of this is Louden and Skeem's (2007) study on juror case judgements and verdicts for insanity cases. This study assessed prototypes of insanity held by jurors, and the utility of attitudes towards the insanity defence in predicting verdicts. Results indicated that attitudes toward the insanity defence powerfully influence jurors' general information processing (Louden \& Skeem, 2007). In this particular study, jurors' attitudes may have prevented them from following instructions to selectively and effectively represent their personal prototypes of insanity. This finding suggests that jurors' attitudes towards the insanity 
defence should be a center of focus for identifying biased jurors in insanity cases and developing methods to bring their decisions into greater accordance with the law (Louden \& Skeem, 2007). The current study sought to expand on this idea by evaluating juror attitudes toward mental illness in general for cases involving defendants with mental illness.

While there is not much in the literature addressing stigma towards mental illness in juror decision-making, we can draw from previous studies in areas such as race (Eberhardt et al., 2006); the insanity defence (Louden \& Skeem, 2007; McGraw \& Foley, 2000; Skeem \& Golding, 2001; Skeem, Louden, \& Evans, 2004); and gender (Schutte \& Hosch, 1997) to get a sense of the importance of juror biases in a legal context. Sometime, the use of stereotypes in impression formation can be controlled effectively by effortful correction processes (Bodenhausen \& Macrae, 1998). One such type of correction process that may be valuable in a juror context could be in the form of a reflective challenge for cause procedure. This idea will be explained in more detail below.

\section{Challenge for Cause}

Jury selection in the Canadian court system is very different from the proceedings in the United States. In the United States, prospective jurors are questioned by attorneys from each side about their background, life experiences, and opinions to determine whether they should be selected for the jury panel. This process in the U.S. is called the voir-dire. Unlike the U.S., prospective jurors in Canada are not typically questioned. In court, prospective jurors are called forward individually and both sides of legal counsel take turns and indicate whether they are content in having that person act as a juror (Rose, 2001). Lawyers can reject a potential juror through two challenge procedures, peremptory or for cause.

Peremptory challenge is a rejection based on the very limited information provided to lawyers in the Canadian judicial system, which includes only the juror's name, address, 
occupation, physical appearance, and demeanour (Vidmar \& Schuller, 2001). Challenge for cause, on the other hand, is a rejection based on a realistic potential and presumption of juror partiality. The Crown and the defence each have a limited number of peremptory challenges, for which no reason needs to be given, and an unlimited number of challenges for cause, which must be proven on specific grounds, such as partiality (Rose, 2001).

To date, in Canada, only the judge in a trial can decide whether to allow a challenge for cause question (though this may be the subject of an appeal) on a case-by-case basis (Rose, 2001). Two cases (see Regina v Parks, 1993; Regina $v$. Williams, 1998) have set a precedent for the potential inclusion of a race challenge for cause in cases with a minority defendant, whereby in some circumstances, a trial judge can take judicial notice of widespread racial prejudice and allow a general challenge for cause regarding racial bias. This is not done automatically however, and the defence still has to persuade the judge that such general prejudice exists. There has not been a general challenge for cause regarding mental illness stigma in Canada -- thus for such a procedure to take place, the accused would have to establish strong evidence of general stigma against people with mental illness that would affect the jurors' impartiality in a trial as grounding for such a challenge.

American research by Crocker and Kovera (2010) examining attitudes towards the insanity defence has recently explored rehabilitating biased jurors in order to make them suitable for selection. The rehabilitation procedure involved providing the potential jurors with the definition of insanity, and asked them whether they could put aside their personal feelings about the insanity defence and base their decisions on the law (Crocker \& Kovera, 2010). Although this study did not find rehabilitation's interaction with juror bias to affect verdict judgements, it did find that the rehabilitative process reduced jurors' confidence in their guilty verdicts (Crocker \& Kovera, 2010). 
A study by Schuller, Kazoleas, and Kawakami (2009), involving racial biases in Canadian court, assessed the effect of no-challenge, a close-ended standard challenge, or a modified reflective pre-trial questioning strategy on bias. The standard challenge for cause involved a single closed-ended question: "Would your ability to judge the evidence in this case without bias, prejudice or partiality be affected by the fact that the person charged is Black?" (Schuller et al., 2009). In comparison, a reflective challenge for cause question instructs participants to consider how bias can influence their judgements, thereby orienting them more toward the process of correction rather than a simple denial of prejudice: "How might your ability to judge the evidence in the case be affected by the fact that the defendant is Black?" Schuller and colleagues (2009) found that only the reflective format demonstrated a reduction in racial bias, and explained that perhaps this more reflective process may prove to be more effective in making people aware of their biases and motivating them to correct their possible prejudices (Schuller et al., 2009).

The challenge for cause procedure in Canada involves accurate juror selfassessments, in terms of their awareness of their bias and its potential to interfere with their decisions, and an honest disclosure of their bias (Vidmar \& Schuller, 2001). Vidmar and Hans' (2007) examination of the voir-dire procedure in the U.S. suggests that limited forms of voir-dire (similar to the standard challenge in Canada) are not very effective at detecting jurors bias. While the more effective reflective types of questioning are common practice in voir-dire proceedings in the United States, in Canada, only standard style challenge questions are permitted. The value behind cognitive reflection is that it involves actively open-minded thinking, and in doing so it interacts with heuristics and characteristics of the situation (Baron, 1985; Campitelli \& Labollita, 2010). A more reflective strategy of challenge may not guarantee more valid assessments of juror biases; however, by instructing participants to consider how bias can influence their judgments, it orients them towards 
questioning their heuristics, and thereby has the potential to influence their thought process, outcomes, and actions.

The idea of a challenge for cause in cases involving a defendant who has a mental illness is an important one to explore, as it will determine whether the procedure can successfully identify individuals who might demonstrate bias, and assess the impact on the decisions of those who pass the challenge screening (Schuller et al., 2009). As mentioned, findings from race research demonstrate that the reflective format can be related to a reduction in bias (Schuller et al., 2009); thus drawing from this research, the present study explored this idea in the context of mental illness.

\section{Current study}

People with mental illness are often treated with suspicion and are generally expected to face discrimination. While there is some American literature addressing juror stigma towards the insanity defence (see Crocker \& Kovera, 2010; Hans, 1986; Louden \& Skeem, 2007), there has been little research in a Canadian context surrounding the issue of defendant mental illness. The issue of potential stigma towards a defendant with a mental illness is not specifically addressed in current judicial proceedings (i.e., Canadian jury selection does not automatically allow for a challenge for cause question regarding stigma towards mental illness; such a question would require approval from the judge on a case by case basis). The purpose of this study was to assess stigma towards mental illness in juror decision-making, and to explore the idea of introducing a challenge for cause question on the topic. Specifically, this study aimed to explore juror stigma and to measure its influence on verdict by also manipulating challenge for cause questioning format. If stigma towards mental illness is found to be detrimental to the impartiality of the verdict, then this problem may be 
abetted through a challenge for cause procedure, to ensure the defendant's right to a fair trial.

\section{Hypotheses}

\section{Hypothesis 1}

There will be a relationship between pre-attitudes and trial decisions (see Louden $\&$ Skeem, 2007). Specifically, higher levels of stigma [as measured by the Attitudes towards People with Mental Illness (APWMI) scale (Kobau et al., 2010)] will be associated with higher levels of guilt certainty, harsher sentences, and less favourable impressions of the defendants with a mental illness.

\section{Hypothesis 2}

There will be an effect of defendant mental illness on trial decisions (verdict, sentencing, defendant likability). Jurors will be influenced by mental illness in the sense that there will likely be differences in bias associated with different types of mental illness. Based on public stereotypes, defendants with schizophrenia are likely to be found guilty more often and given harsher sentences than those with obsessive compulsive disorder (OCD) or depression (Angermeyer et al., 2004; Angermeyer \& Dietrich, 2006; Corrigan et al., 2000; Crisp et al., 2000). Overall, all three mental illness groups will be treated more harshly than the group where the defendant does not have a mental illness (Corrigan et al., 2000, Phelan \& Link, 2004).

Hypothesis 2a. We are expecting to see that attitudes predict behaviour in Hypotheses 1 and 2. This will be further verified by checking to see if the relationship between defendant mental illness and trial decisions is reduced or eliminated after controlling for attitudes. Since stigma towards mental illness is known to influence behaviour (Corrigan et al. 2000, Phelan \& Link, 2004), correcting for stigma should 
demonstrate differences in the trial decisions made by the jurors compared to when stigma is not controlled for.

\section{Hypothesis 3}

We expect to find a number of effects for challenge type.

Trial decisions. Concerning trial decisions, it is anticipated that the challenge for cause procedure will be effective in reducing discrimination, specifically that those in the reflective challenge group will show less bias than those in the standard-challenge or nochallenge groups in their verdict and sentencing decisions. Participants in the latter two groups will likely find defendants with mental illness guilty more often than those in the reflective challenge group (Schuller et al., 2009).

Stigma. The type of challenge for cause will have an effect on stigma. Specifically, it is projected that those in the reflective group will show a reduction in stigma from their pre and post ratings on the APWMI scale.

Confidence. It is also expected that because they are questioned about their potential for partiality and therefore may second-guess themselves, those in the standard and reflective challenge conditions will demonstrate lower confidence ratings in their decisionmaking (Crocker \& Kovera, 2010) than those in the no-challenge condition.

\section{Hypothesis 4}

We will explore whether the challenge for cause procedure works for stigma towards some mental illnesses and not others, but given that this has not yet been examined in this context, no specific predictions can be made about this potential interaction. 


\section{Method}

\section{Participants}

In hopes of conducting a study with strong validity, 200 participants ( 10 conditions $\mathrm{x}$ 20 participants/condition) were drawn from a university sample of jury-eligible students. Participants were $77 \%$ female, $22.5 \%$ male, and $0.5 \%$ transgendered, and ranged in age from 18 to $53(\mathrm{M}=20.38, S D=4.04)$. The racial background was mixed, with $80 \%$ Caucasian, 5.5\% Asian, 2.5\% Black, 3.0\% Middle Eastern, 2\% Aboriginal, 1.5\% East Indian, $1.0 \%$ Hispanic, and $4.5 \%$ who identified themselves as "Other". While $90.9 \%$ of participants did not personally have a mental illness $(9.1 \% \mathrm{did}), 67.5 \%$ knew someone or had interactions with someone who did have a mental illness. Recruitment of participants was conducted through the SONA system, and students received 0.5 credits for their participation. This study was completed online using SurveyMonkey, and participants were emailed the study link via the primary investigator's email account. While in real cases, jurors are randomly selected from the public and deliberation takes place in decision-making, research does suggest that a simulation method, or the use of undergraduates, does not influence results (Bornstein, 1999). The use of the Web for online studies has also shown to be comparable to in-lab research (Birmbaum, 2000; Buchanan \& Smith, 1999; Riva, Teruzzi, \& Anolli, 2003; Smith \& Leigh, 1997), and thus should not pose a problem for this study. To confirm the validity of this study, a comparison between online and in-lab methods was conducted on a sample of 120 participants, with 60 in each simulation method. This comparison was conducted on three condition groups with 20 participants in each (no mental illness/no challenge, depression/reflective challenge, \& schizophrenia/standard challenge). This comparison demonstrated justification for online research with no significant differences found between the online and in-lab groups, in terms of verdict decisions $[t(118)=.75, p>$ 
$.10]$, pre attitude scores $[t(117)=1.75, p>.05]$, or post attitude scores $[t(117)=1.13, p>$ $.10]$, and consequently the study proceeded with the online method. Additional safeguards were used to eliminate any remaining doubts about the validity of this data collection method (such as individual, environmental, and technical factors). This included eliminating data for analyses from participants who finished the online study in less than 20 minutes, or who failed the manipulation checks. A time cut-off was used as per Levett and Kovera (2008) to ensure that participants had attended to the stimulus materials. The 20 minute time was determined as a realistic cut-off based on an online pilot-testing of three study conditions. Four research assistants took 27-38 minutes to complete the study, with an average completion time of 32 minutes. Based on that information, and given that some participants may be slower or faster readers, completion of the survey in less than 20 minutes was deemed unrealistic, and would therefore be used to identify participants who did not read the materials and did not reliably answer the questionnaire.

Manipulation check. Without reference to preceding trial materials, participants were asked to indicate what mental illness the defendant was described as having, as well as other details in the case, such as: what happened to the victim, what was stolen etc. [See Appendix $F$ for complete questions). Looking at frequency descriptive statistics, participants who failed the manipulation checks were removed from subsequent analyses.

\section{Materials}

The Attitudes towards People with Mental Illness (APWMI) scale (Kobau et al., 2010) was used in this study to assess stigma towards mental illness. This scale was based on the British Omnibus National Survey (Crisp et al., 2000), which was designed to assess the familiarity of people with some of the most common mental illnesses. For reasons of generalizability, the scale itself was created with no specifications made regarding the type of mental illness. Participants are expected to self-define the construct of mental illness. This 
generic, multidimensional, and brief instrument consists of 11 questions, and has demonstrated rigorous convergent validity (Kobau et al., 2010). The scale items were found to load onto two factors (1) Negative Stereotypes, and (2) Recovery and Outcomes. Cronbach's alpha was 0.69 and 0.66 , respectively, which demonstrated an acceptable estimate for internal consistency (Kobau et al., 2010). Each factor is comprised of five item questions. Examples of the items in the scale are listed below, and for each statement, participants answer based on a 5-point Likert scale, where $1=$ strongly disagree, and $5=$ strongly agree. See Appendix $\mathrm{C}$ for the full scale.

- I believe a person with mental illness is a danger to others

- I believe a person with mental illness would improve if given treatment and support

- I believe a person with mental illness is unpredictable

- I believe a person with mental illness has only himself/herself to blame for his/her condition

In hopes of not disclosing the true nature of the study to participants, other legal attitudes and filler questions from the Attitudes Towards the Death Penalty Scale (O'Neil, Patry, \& Penrod, 2004), the Need for Cognition Scale (Cacioppo, Petty, \& Kao, 1984), and the Belief in a Just World Scale (Rubin \& Peplau, 1975) were mixed into one questionnaire along with the APWMI scale. These questions were all taken from pre-established questionnaires, and items were adapted to a Canadian context [e.g., It is a common occurrence for a guilty person to get off free in Canadian courts]. See Appendix C for the complete questionnaire [Note: the *items identify the APWMI questions].

As mentioned, there were three challenge for cause conditions: No challenge, Standard challenge, and Reflective challenge. The challenge for cause questions were 
formatted and used as per Schuller et al. (2009). See Appendix D for the three challenge conditions and their specific questions.

The trial transcript highlighted the court proceedings, including statements, arguments, and questioning from both the Crown and the defence regarding defendant Benjamin Smith's robbery charge. This transcript had been pilot-tested, which revealed an even verdict split in the absence of manipulations (to avoid ceiling or floor effects). During the defendant's testimony, he states that on the night of the crime, he had dinner, went jogging, then watched television. The jogging is also his alibi for why muddy running shoes, with matching treadmarks to those from the crime scene, were found in his apartment. The manipulation of the mental illness of the defendant was depicted as "I like to jog at night because it is cooler and quieter. It helps to calm me down, and my psychiatrist recommended it to help me deal with my depression. "- See Appendix E for the full transcript and all four manipulations.

The juror questionnaire consisted of a range of questions or items created by the researchers about the participant's confidence and impression ratings (case judgements) as well as demographic information (i.e., age, gender, ethnicity etc.). These items have reliably been used in previous studies. For the full questionnaire, please see Appendix F.

\section{Procedure}

Upon initial recruitment via SONA, participants were screened to ensure juroreligibility (i.e. age, Canadian citizenship, and a strong comprehension of the English language). After screening and participant sign-up, participants were emailed the Survey Monkey link to access the study. Participants were required to enter the ID number that was provided to them to begin the study. At the beginning of the study, consent was obtained by providing individuals with a consent form for them to read and they had to check off a box if 
they wished to participate, giving them the opportunity to opt out at any point. The consent form also outlined how participant anonymity would be ensured by assigning them an ID number that was not associated with their names, and how their confidentiality would be ensured by storing all study documents on a password protected website.

After consent was obtained, a baseline assessment of participants' attitudes was carried out using a questionnaire that included the APWMI scale and various filler items, so as to not alert the participants to the true nature of the study. Using a simulated jury paradigm, this study randomly assigned participants (a.k.a. mock jurors) to one of the three challenge for cause groups, and subsequently participants read a brief trial transcript describing a Robbery charge. The defendant's mental illness was manipulated in each case. Participants were asked to make a judgement about the defendant's guilt (guilty/not guilty) based on the evidence provided, and following were asked to evaluate confidence ratings about their decision. If a guilty verdict was given, participants were asked a follow-up question regarding the sentencing (imprisonment/no punishment, and sentence length in years). Regardless of their verdict decision, participants also completed a brief questionnaire that addressed their impressions of the information presented at trial (e.g., the evidence, the victim and defendant testimonies), and of the defendant (e.g., likability, intelligence, cruelty). At this point, participants did a post-test of the APWMI scale. Finally, participants provided demographic information such as gender, age, ethnicity, race, education, religion, occupation, and whether they or anybody they know has a mental illness.

\section{Design}

A 4 [Defendant mental illness: No mental illness, Depression, Schizophrenia, Obsessive Compulsive Disorder (OCD)] x 3 [Challenge for Cause groups: No challenge, Standard challenge for cause question about attitudes, Reflective challenge for cause 
question about attitudes] between-subjects factorial design was used to examine verdict and sentencing decisions of mock jurors.

Creation of variables. To obtain a more sensitive measure of guilt, a continuous verdict rating was calculated by multiplying the dichotomous $(-1=$ not guilty,$+1=$ guilty $)$ verdict by the participants" rating of verdict confidence (ranging from 0 "not at all confident" to 10 "very confident"). This produced a 20 -point scalar measure of verdictconfidence $(+10$ reflecting complete confidence in the defendant's guilt, -10 reflecting complete confidence that the defendant is not guilty). Scales for testimony credibility, evidence credibility, and defendant impressions were also made (rated 1 to 9), with some items needing to be reverse-coded. These scales were checked for adequate reliability (all Cronbach alphas were $>.70$ ) before combining scores for overall ratings of credibility and impressions, such that higher scores indicated greater credibility and likability. As per Kobau et al. (2010), to facilitate comparison on the APWMI, five items were reverse coded for analyses, so that higher scores represented more negative attitudes. The full range of possible scores on the APWMI is from 0 to 55 . Sentence length was decided in years or as a life sentence, where life sentences were entered as 25 years for the analyses.

\section{Results}

A total of 281 students participated in the study. Of these, $81(28 \%)$ failed one or more manipulation check, and therefore only the 200 who passed the manipulation checks were included in the analyses. A total of $48 \%$ of the participants who failed the manipulation checks also completed the survey in 20 minutes or less. After accounting for those $48 \%$, the remaining total failure rate of $15 \%(42 / 281)$ in the complete online sample is comparative to the failure rate of $12 \%$ in the sample collected in the lab (of which none finished in under 20 minutes). When examining the fails per condition, there were 3 fails in 
the No MI/No Challenge condition; 8 fails in Depression/No Challenge; 10 fails in Depression/Standard; 10 fails in Depression/Reflective; 6 fails in Schizophrenia/No Challenge; 7 fails in Schizophrenia/Standard; 5 fails in Schizophrenia/Reflective; 17 fails in OCD/No Challenge; 9 fails in OCD/Standard; and 6 fails in the OCD/Reflective condition. The breakdown of fails per MI and per Challenge type separately can be found in Table 1 below. To make up for the manipulation check fails, participant recruitment was ongoing until there were adequate cell sizes of at least $20 /$ condition that passed.

Table 1. Failed Manipulation Checks per Mental Illness and Challenge Condition

\begin{tabular}{lc}
\hline & \# of Failed Manipulation Checks \\
\hline No Mental Illness & 3 \\
Depression & 28 \\
Schizophrenia & 18 \\
OCD & 32 \\
No Challenge & 34 \\
Standard Challenge & 26 \\
Reflective Challenge & 21 \\
\hline
\end{tabular}

Paired-Samples t-test revealed that there was no significant difference between Pre and Post attitude scores on the APWMI scale, $[t(198)=0.69, p>.10]$, with mean pre scores of $26.85(S D=3.74)$, and mean post scores of $26.83(S D=4.08)$. With possible scores on the APWMI ranging from 0 to 55 (with higher scores representing more negative attitudes), means on both the pre and post scores indicated that this sample had overall moderately negative attitudes toward people with mental illness. Point biserial correlations revealed a marginally significant relationship between participants who disclosed personally having a 
mental illness and lower overall pre-attitudes scores (more positive attitudes) towards mental illness $\left(r_{p b}=-.14, p=.05\right)$. There was no relationship between participants knowing someone with a mental illness and attitude scores.

Correlation analyses were conducted on various variables to address Hypothesis 1, which examined whether there is a relationship between pre-attitudes and trial decisions (see Table 2). Specifically, correlations between pre-attitude levels [as measured by the APWMI scale], mental illness, challenge type, continuous verdict, dichotomous verdict (using point biserial correlations), guilt scale, sentencing (using point biserial correlations), and impressions of the defendants were evaluated.

Table 2. Relationship of Variables as Demonstrated by Correlation Analyses

\begin{tabular}{|c|c|c|c|c|c|c|c|c|}
\hline & $\begin{array}{c}\text { Pre- } \\
\text { Stigma }\end{array}$ & MI & Challenge & Verdict & $\begin{array}{l}\text { Cont. } \\
\text { Verdict }\end{array}$ & $\begin{array}{l}\text { Guilt } \\
\text { Scale }\end{array}$ & $\begin{array}{c}\text { Sentence } \\
\text { Type }\end{array}$ & $\begin{array}{c}\text { Def. } \\
\text { Likable }\end{array}$ \\
\hline Pre-Stigma & - & .03 & -.05 & .12 & .14 & $.19 * *$ & .07 & -.10 \\
\hline MI & .03 & - & - & -.01 & -.04 & .26 & .87 & .75 \\
\hline Challenge & .05 & - & - & .53 & .39 & .19 & .47 & .26 \\
\hline Verdict & .12 & -.01 & .53 & - & $.96 * *$ & $.69 * *$ & $.22^{*}$ & -.13 \\
\hline $\begin{array}{l}\text { Cont. } \\
\text { Verdict }\end{array}$ & .14 & -.04 & .39 & $.96 * *$ & - & $.74 * *$ & $.81^{* *}$ & $-.59 * *$ \\
\hline Guilt Scale & $.19^{* *}$ & .26 & .19 & $.69 * *$ & $.74^{* *}$ & - & $.68 * *$ & $-.53 * *$ \\
\hline Sentence & .07 & .87 & .47 & $.22^{*}$ & $.81^{* *}$ & $.68 * *$ & - & $-.54 * *$ \\
\hline $\begin{array}{c}\text { Def. } \\
\text { Likeable }\end{array}$ & -10 & .75 & .26 & -.13 & $-.59 * *$ & $-.53 * *$ & $-.54 * *$ & - \\
\hline
\end{tabular}


Overall this participant sample was relatively lenient, with $63 \%$ deciding the defendant was not guilty, regardless of mental illness or challenge condition. Participant overall neutrality was also demonstrated by ratings on the continuous verdict variable (Range -10 to $+10 ; \mathrm{M}=-1.55 ; S D=6.91$ ), and guilt scale variable (Range 0 to $100, \mathrm{M}=$ $54.22, S D=30.42$ ). The distribution for defendant likability was normal, and ranged from scores of 25 to $100(\mathrm{M}=68.09, S D=14.44)$. Expectedly, likability scores were negatively correlated with both dichotomous verdict $\left(r_{p b}=-.57, p<.001\right)$ and continuous verdict $(r=-$ $.59, p<.001$ ), whereby lower scores of likability were associated with increased ratings of defendant guilt. Correlational analyses revealed that pre attitudes related only with scale of guilt $(r=.185, p<.05)$, whereby higher (more negative) attitudes was correlated with higher ratings of guilt on this scale.

\section{Dichotomous Verdict and Sentencing Decisions}

To determine whether the verdicts varied as a function of defendant mental illness condition and/or challenge condition, these variables were dummy coded for the analyses. Logistic regressions were conducted to explore whether stigma ratings, mental illness categories, and/or challenge conditions were good predictors of the dichotomous verdict and sentencing variables (Hypotheses 2, 3a, 3c, and 4). First looking at verdict, a test of the full model against a constant only model was not statistically significant, with no significant predictors $(p>.05)$ in Variables not in the Equation of Block 0, indicating that the predictors do not distinguish between guilty and not-guilty verdict ratings $\left(X^{2}(6)=5.72, p>.10\right)$. Neglekerke's $\mathrm{R}^{2}$ of .039 indicates a very weak relationship between verdict prediction and mental illness, attitudes, and challenge type. Due to the non-significance, and the inability for these variables to contribute to the prediction of verdict, the analyses were terminated at this point. 
When sentencing was subjected to a separate logistic regression, a test of the full model against a constant only model was not statistically significant, with no significant predictors $(p>.10)$ in Variables not in the Equation of Block 0, indicating that the predictors do not distinguish between imprisonment and no-punishment sentence types $\left(X^{2}(6)=5.02, p\right.$ $>$.10). Neglekerke's $R^{2}$ of .056 indicates a very weak relationship between sentence prediction and mental illness, attitudes, and challenge type. Due to the non-significance, and the inability for these variables to contribute to the prediction of sentence type, the analyses were terminated at this point.

\section{Continuous Ratings}

A series of ANOVAs (4 defendant condition MI x 3 challenge conditions) were conducted on the dependent measures (continuous verdict, sentence length, \& defendant likability) to further address Hypotheses 2, 3a, 3c, and 4. The assumptions of homogeneity of variance, independence, and normality were checked. The first two assumptions were met. Histograms examining normality suggested that this assumption was not met, however because these were based on valid data-points, normality was deemed adequate to proceed with analyses.

Continuous verdict. First, to explore the effects of $\mathrm{MI}$ and Challenges on verdict when taking into account participants' confidence in their decisions, an ANOVA was conducted using continuous verdict as the dependant variable. Results showed that neither defendant mental illness $[F(3,189)=1.17, p>.10]$, nor challenge type $[F(2,189)=.91, p>$ .10] had a significant effect on continuous verdict. There was no significant interaction of mental illness and challenge type on continuous verdict, $F(4,189)=.13, p>.10$. Trends of the effects of mental illness (Figure 1) and of challenge type (Figure 2) on verdict are displayed below. 


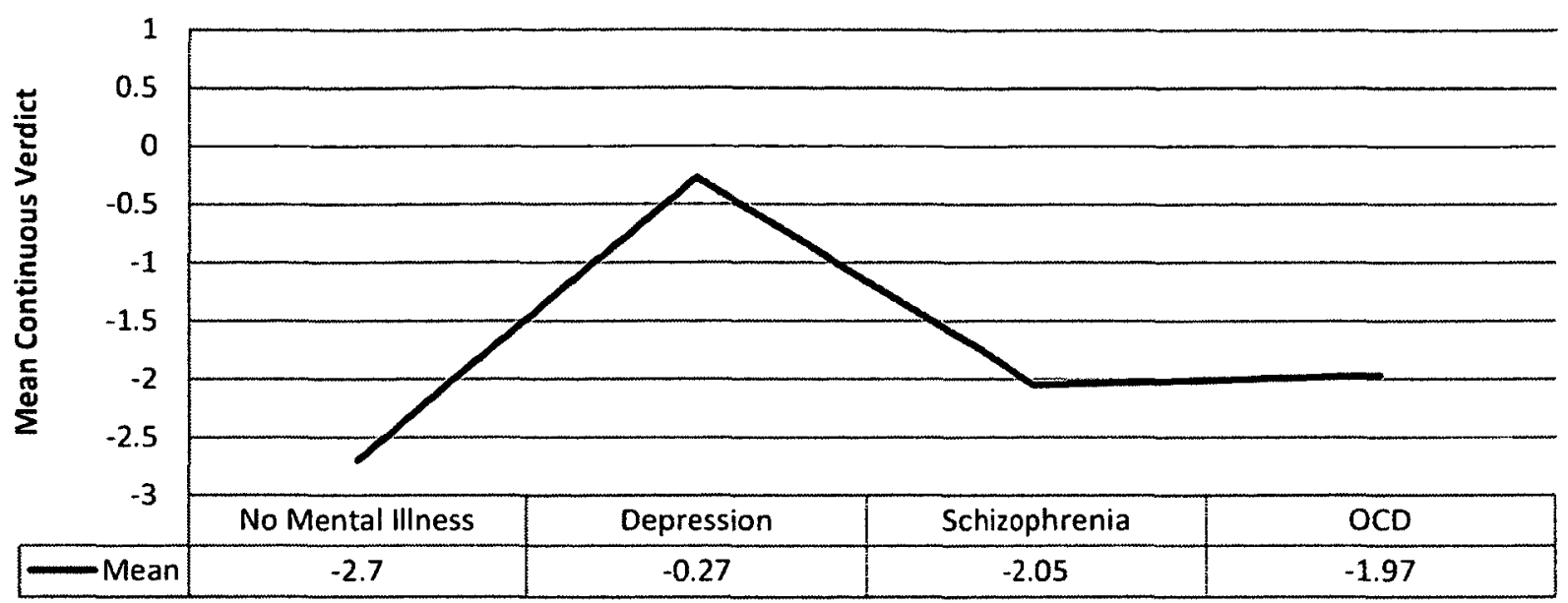

Figure 1. Mean Continuous Verdict Across Mental Illness Conditions

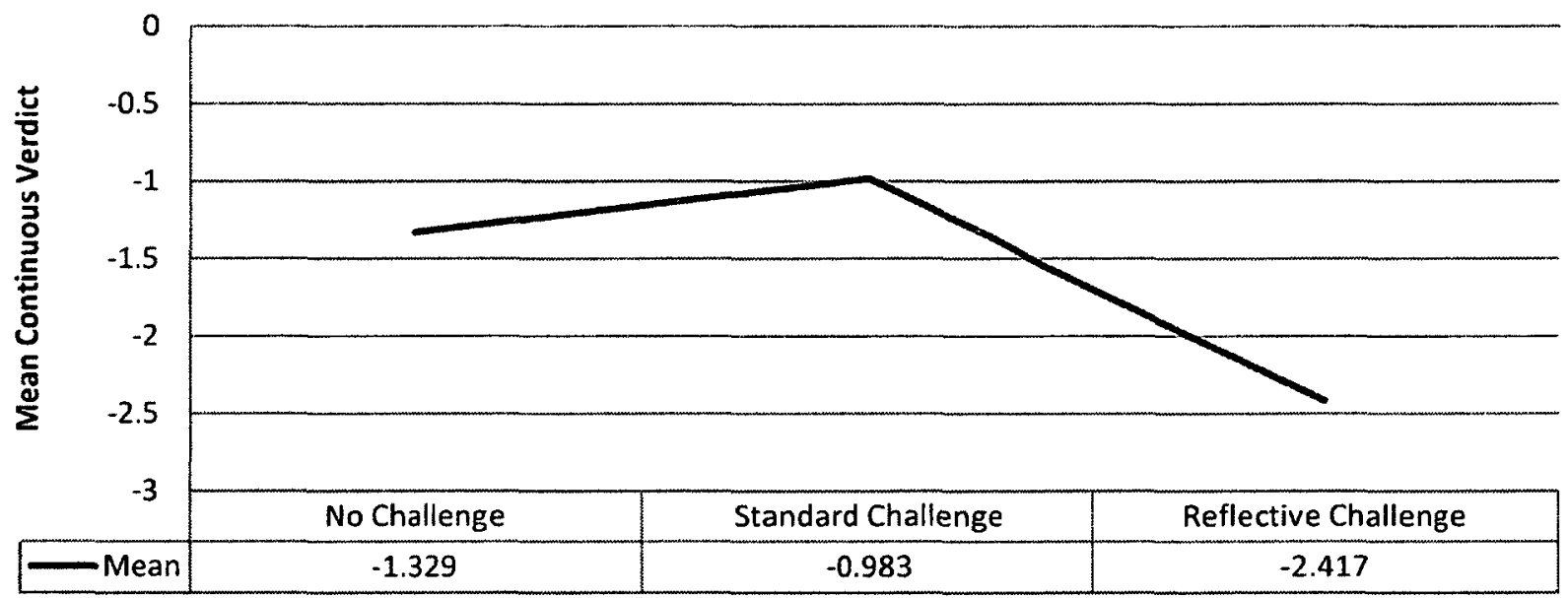

Figure 2. Mean Continuous Verdict Across Challenge for Cause Procedures

Sentence length. A single outlier was identified for the sentence length variable.

Sentence lengths were overall low $(\mathrm{M}=3.06, S D=3.42)$ ranging from 0 to 10 years with the exception of one life sentence recommendation (value of 25 years). Analyses were run with the value of 25 included, with the value deleted, and also with the value corrected by replacing it with the group mean +3 MSE. Results were similar in each case, meaning that the results were not driven by this value, and therefore it was deemed appropriate to keep it 
in the data set in its original value for analyses. When examining sentence length decisions there was no significant effect of $\operatorname{MI}[F(3,59)=1.09, p>.10]$, or challenge type $[F(2,56)=$ $.86, p>.10]$ on sentence length; and no significant interaction $[F(4,59)=1.08, p>.10]$. Trends of the effects of mental illness and of challenge type on sentence length are displayed in Figure 3 and Figure 4, respectively, below.

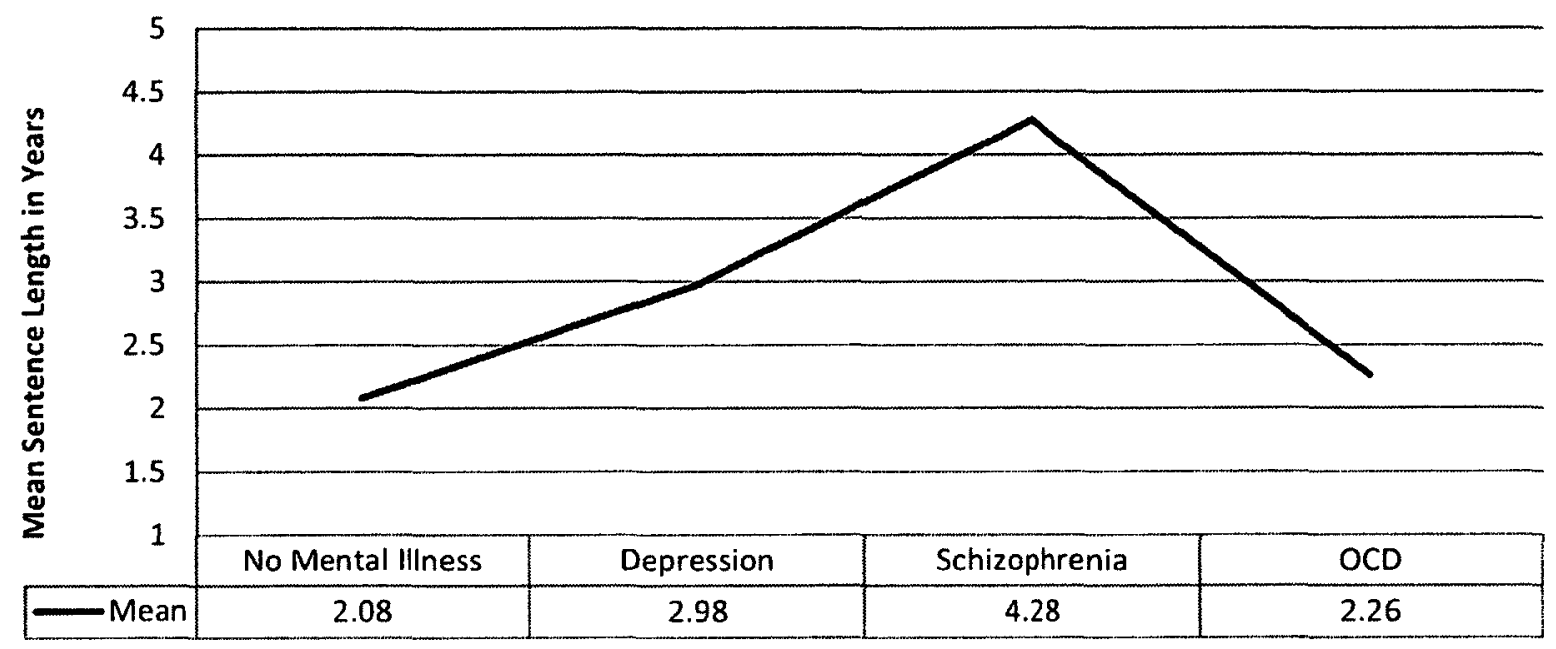

Figure 3. Mean Sentence Length in Years Across Mental Illness Conditions

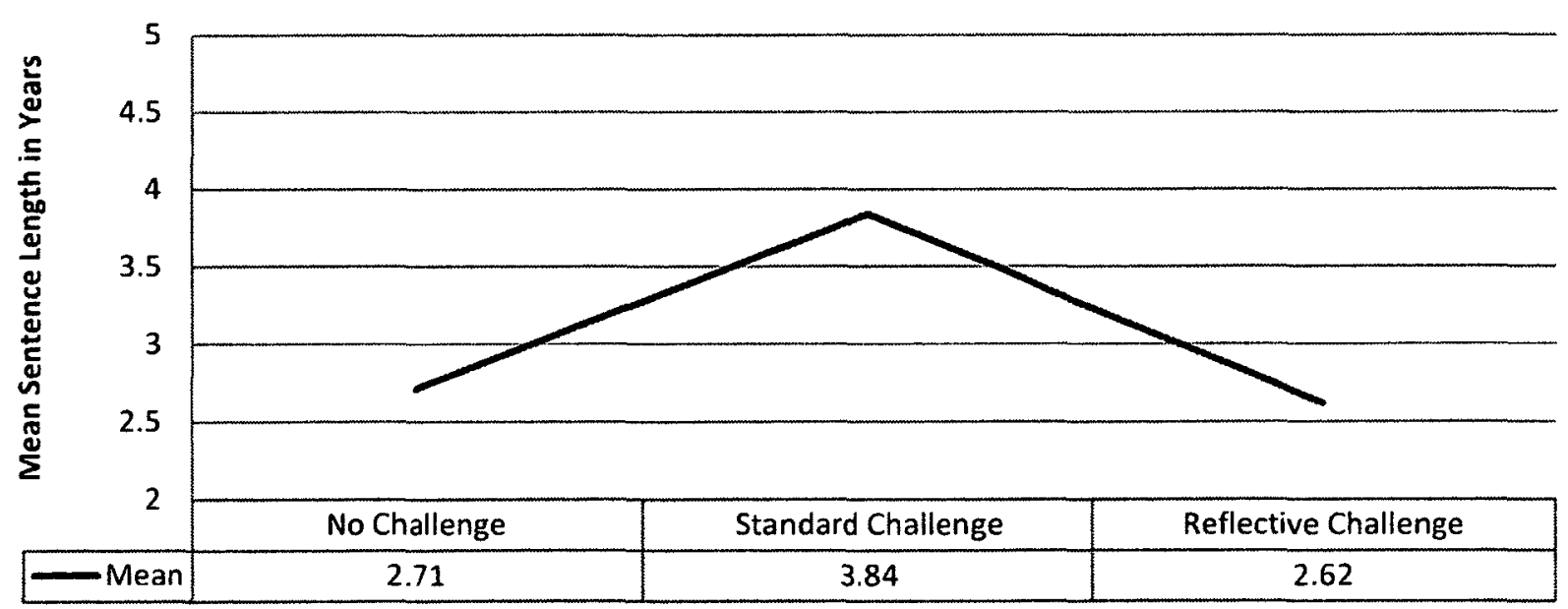

Figure 4. Mean Sentence Length in Years Across Challenge for Cause Procedures

Defendant likability. When defendant likability was subjected to an ANOVA, results showed that neither $\mathrm{MI}[F(3,190)=.21, p>.10]$ nor challenge type $[F(2,190)=1.50$, 
$p>.10]$ had a significant effect on defendant likability. There was no significant interaction of mental illness and challenge type on defendant likability, $F(4,190)=.42, p>.10$. Trends of the effects of mental illness and of challenge type on defendant likability are displayed in Figure 5 and Figure 6, respectively, below.

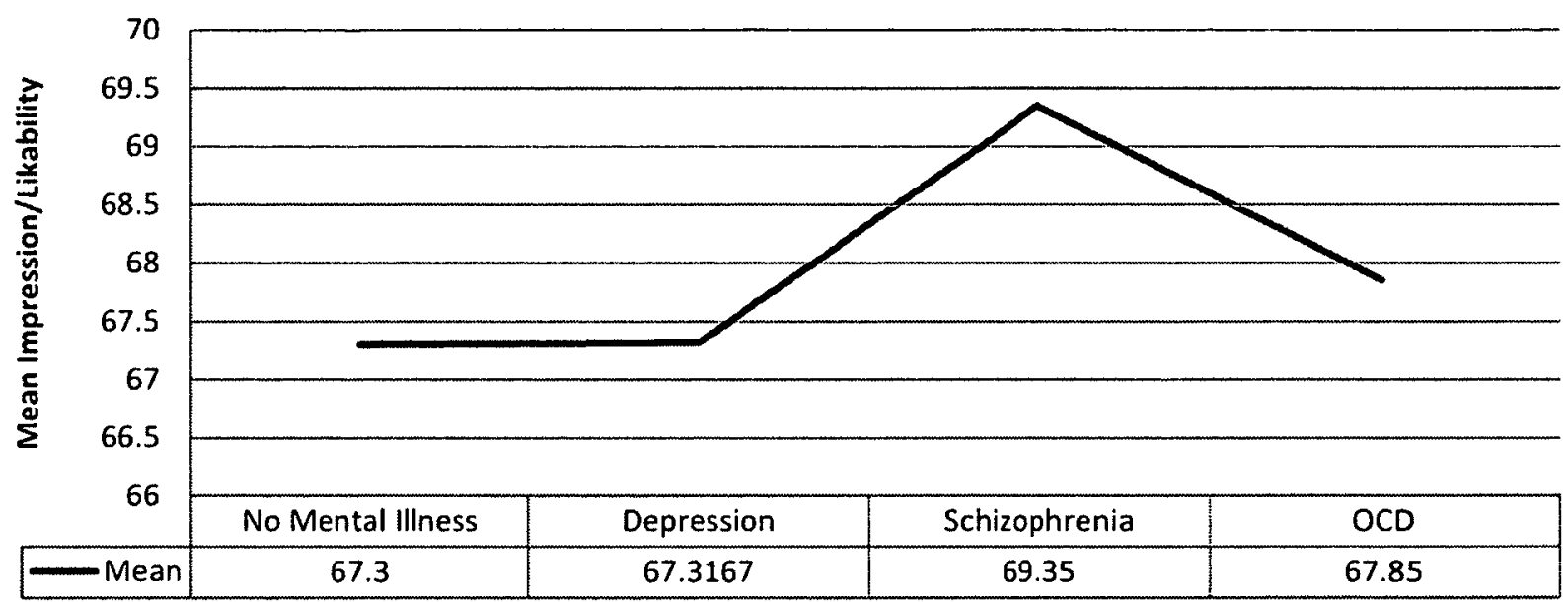

Figure 5. Mean Impressions of the Defendant Across Mental Illness Conditions

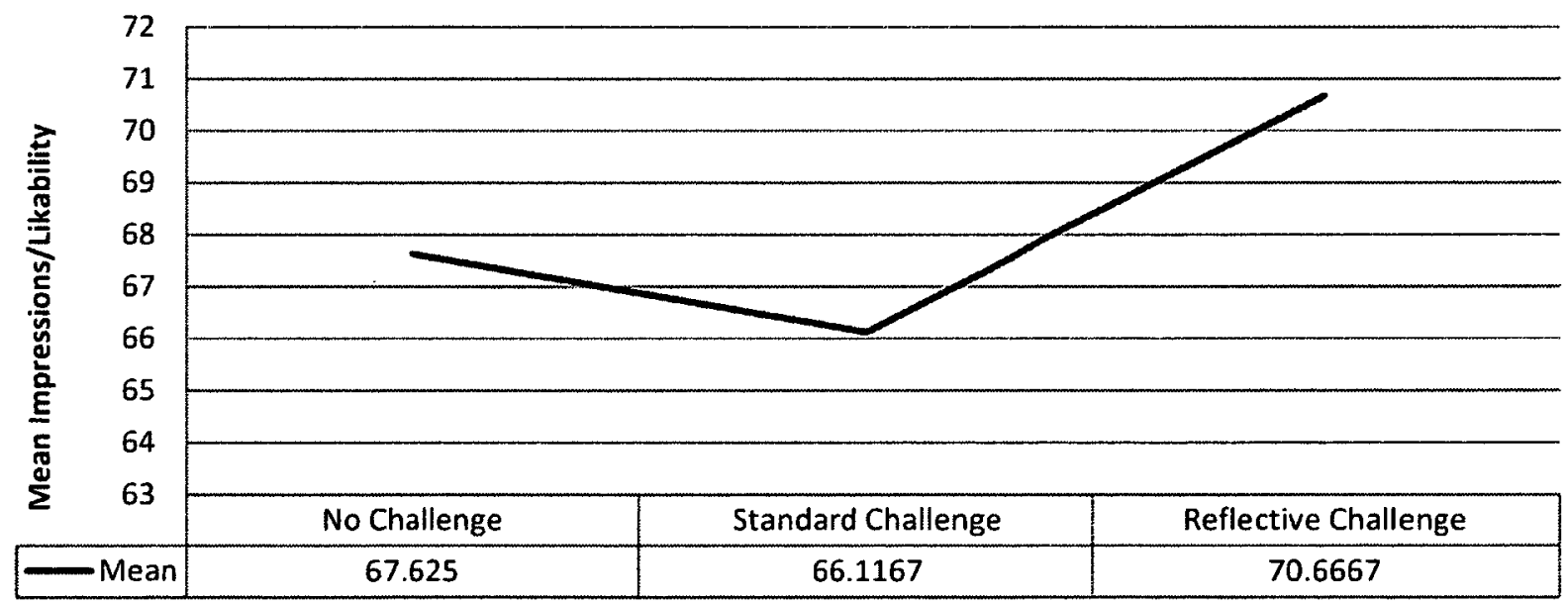

Figure 6. Mean Impressions of the Defendant Across Challenge for Cause Procedures 


\section{Effect of Stigma on Trial Decisions}

To explore the effect of stigma on trial decisions in Hypothesis 2a, a series of ANCOVAs were conducted on the continuous verdict, sentence length, and defendant likability, with MI \& Challenge as predictors again and using Pre-Attitude scores as the covariate. When controlling for Attitudes Towards Mental Illness, defendant mental illness did not have a significant effect on continuous verdict, $F(3,187)=.88, p>.10$, nor did challenge type $F(2,187)=.92, p>.1$. Using attitudes as the covariate, there was also no significant interaction of mental illness and challenge type on continuous verdict, $F(4,187)=$ $.14, p>.10$. Examining sentence length decisions while controlling for attitudes reveals similar results, with no significant effect of $\operatorname{MI}[F(3,58)=1.11, p>.10]$ or challenge type $[F(2,58)=.97, p>.10]$, and no significant interaction $[F(4,58)=1.06, p>.10]$. When defendant likability was subjected to an ANCOVA with the same predictors, results show that neither $\operatorname{MI}[F(3,188)=.28, p>.10]$ nor challenge $[F(2,188)=1.66, p>.10]$ had a significant effect on defendant likability. There was no significant interaction of mental illness and challenge type on defendant likability when controlling for attitudes, $F(4,188)=$ $.44, p>.10$.

\section{Influence of Challenge Procedures on Pre-Post Attitudes}

To determine the influence of the challenge for cause procedure on stigma (Hypothesis $3 b$ ), we explored whether individuals in different challenge conditions would experience changes in stigma following the challenge procedure. This was addressed by a separate ANCOVA conducted on pre/post-test stigma scores. For this analysis, the post-test measurement was the response, the treatment/challenge condition was the design factor, and the pre-test was the covariate (see Dallal, 2005). Pre and post attitude scores analyzed in this 
ANCOVA revealed that when controlling for pre-attitudes, challenge type did not significantly affect the post-attitudes towards mental illness, $F(2,195)=3.69, p>.10$.

\section{Discussion}

Overall, stigma towards mental illness was not identified, and there were no effects of challenge for cause procedures. Reasons for the lack of findings are addressed in this section, although it is possible that there is no good explanation for these results. It was first hypothesized that there would be a relationship between attitudes and trial decisions specifically, that higher levels of stigma would be associated with higher levels of guilt certainty, harsher sentences, and less favourable impressions of the defendants with a mental illness. This was partially supported by the correlational analyses. Specifically, results show that regardless of defendant mental illness, higher levels of stigma (i.e., higher pre-scores on the APWMI) were associated with higher ratings on the guilt scale. It is unclear why contrary to hypothesis pre-attitudes were not related to verdict, continuous verdict, sentence type, or impressions of the defendant. It is possible that the attitude construct used is not predictive of legal outcomes, or perhaps that participant decisions were simply not influenced by their attitudes.

The overall moderately negative views of mental illness, as demonstrated by the average/low stigma ratings pre and post, may be an issue inherent in the sample population for this study. These moderately negative attitudes and the absence of effects found for MI conditions may speak to the fact that participants were psychology students. Although the literature is inconsistent, research has suggested that courses in psychology can bring about more favorable attitudes towards mental illness in students (Dixon, 1967; Kendra, Cattaneo, \& Mohr, 2012). This suggests that perhaps the sample used in the current study might possibly be fairly educated about mental illness, and therefore, inherently less biased, 
compared to the general public (Yeap, 2008). Social desirability was not expected to be at play here because of the more removed nature of online studies - however, participants may have succumbed to the beliefs that are expected of students in psychology and may have felt obligated to uphold those views. The stereotype-consistent theory, which provided the basis for this study, was not supported by the results. The effects of this idea may have been washed out by the psychology student sample, and their preconceptions (or social desirability notions) about mental illness. Future studies could explore the premises above by replicating findings with a community sample.

The literature suggests that individuals who have a mental illness, or who know someone who does, tend to have less negative attitudes about mental illness (Angermeyer \& Dietrich, 2006; Link \& Cullen, 1986; Phelan \& Link, 2004). This idea was only partially replicated in this study, where personally having a mental illness was correlated with lower attitude scores, whereas knowing somebody with a mental illness was not an influential factor on their attitudes as measured by the APWMI scale. The correlation between personally having a mental illness and having more positive attitudes towards it is reasonable in itself; however the absent relationship with knowing someone with an $\mathrm{MI}$ is more difficult to explain. It could be argued that knowing someone with a mental illness (such as depression, anxiety, bipolar, ADHD) is not taken as seriously because it is very common these days, and therefore may possibly be seen as 'normal'. Perhaps commonality and the high frequency of diagnosis in itself may elicit negative attitudes, whereby participants consider the mention of $\mathrm{MI}$ in the trial as an excuse or 'an out'. In addition, knowing someone with a mental illness may not transfer attitudes across groups, as suggested by research by Corrigan et al. (2000), which found that the positive effects of contact with a member of one group (e.g., persons with depression) would not necessarily generalize to a different group (e.g., persons with schizophrenia). 
It was also hypothesized that defendant mental illness and attitudes would affect trial decisions. Previous research has suggested that the public's stereotypes of mental illness include dangerousness and unpredictability, and that these negative views are related to society's stigma surrounding MI (see Angermeyer \& Dietrich, 2006; Stuart 2003). Results from examination of the dichotomous verdict and sentencing, as well as the continuous verdict, sentence length, and defendant impressions, suggest that this hypothesis was not supported as mental illness did not have a significant effect on trial decisions. Regardless of pre-attitudes, the participants were not influenced by the defendant's mental illness. Various mental illnesses are typically viewed differently in society, with schizophrenia being the most associated with "scariness" and dangerousness (e.g. Fiske, 2011). When examining the trends of verdict for the different mental illness conditions, outcomes were not as expected (See Figure 1). Although not significant, the no mental illness condition defendant was treated the least harshly on average compared to the mental illness groups, and the defendant with depression was treated most harshly, instead of the defendant with schizophrenia as originally hypothesized. Similarly, when examining the non-significant trends of defendant likability, the defendant with schizophrenia had the highest overall impression ratings (i.e., was seen as more likable), followed by the defendant with OCD (See Figure 5). The defendants with no mental illness and with depression were rated the least likable. It is unclear what accounted for these trends. Although findings were not significant, it is possible that social desirability or sympathy explain the higher likability ratings of the defendant with schizophrenia in this sample of psychology students. The absence of a mental illness may have made the defendant seem guilty and less likable, possibly because without a MI "excuse" he was perceived as just an ordinary offender. Because depression is seen as commonplace in today's society, it may have been viewed in a similar fashion to the defendant with no mental illness. 
When examining sentence length across mental illness conditions (See Figure 3), the non-significant trends were found to be in line with the hypotheses. For this variable, the defendant with schizophrenia was given the harshest sentence, followed by depression, and OCD and No MI. Although findings were not significant, the inclination for the defendant with schizophrenia to not get the most guilty verdicts and to be viewed most positively, but to get the harshest sentences, may tap into conceptions of legal guilt or criminal responsibility, whereby participants may be questioning mens rea ("guilty mind"; the mental component of a crime). According to this idea, participants may be more likely to consider the defendant with schizophrenia as not responsible for his actions and therefore not guilty of them, but when they do find him guilty, the high sentences suggest expectations of dangerousness and unpredictability. Some literature suggests that it is at sentencing where most biases are visible (Mazzella \& Feingold, 1994; Mitchell, Haw, Pfeifer, \& Meissner, 2005), and although mental illness did not significantly affect sentence type and length, the trends demonstrate that perhaps sentencing is a more sensitive measure for examining attitudes and bias towards mental illness. Of importance to note is that, in real cases, sentencing is the duty of judges rather than of juries, and so the usefulness of the results demonstrating the trending biases of defendants' mental illness on punishment recommendations is that they may be generalizable to sentences rendered by judges (Mazzella \& Feingold, 1994).

In their review of the literature, Angermeyer and Dietrich (2006) found that, generally, the course of mental disorders is seen pessimistically in the absence of treatment, but that the expected deterioration of the mentally ill person's state is reversed when an appropriate treatment is provided (Angermeyer \& Dietrich 2006). Following this belief, another possible explanation for the trends identified above and for why mental illness did not have an effect on verdict is because there may be a more positive view towards mental 
illness when the person is seeking psychological help. In the trial transcript for this study, the defendant states that he runs because his psychiatrist recommended it to help him deal with his mental illness. Although this is a speculative suggestion, it is possible that participants may have noted that the defendant was seeking treatment, and in following, had more optimistic views about the defendant and did not view the mental illness as an influential factor in the trial.

It was expected that challenge type would affect trial decisions, stigma levels, and verdict confidence. Specifically, it was hypothesized that the challenge for cause procedure would be effective in reducing discrimination - those in the reflective challenge group would show less bias than those in the standard-challenge or no-challenge groups in their verdict and sentencing decisions (see Schuller et al., 2009). These suggestions were not supported when examining the results for the guilty/not guilty verdict decision, and this was further recognized even when taking into account juror confidence by using the continuous verdict. Challenge for cause procedures were not effective in reducing discrimination, with no significant difference found between the reflective, standard, and no-challenge groups in their verdict decisions and guilt ratings. Separate examination of pre and post attitude scores revealed that challenge procedures did not have a significant influence on stigma. Similarly, the expectation that the challenge for cause procedures would work to improve stigma towards some mental illnesses and not others, was not supported due to the overall absence of effects of the challenge procedure, mental illness and stigma. The challenge types and formulation were adapted from Schuller et al.'s (2009) effective model, and although this format has only been used in this aforementioned study, the challenge design is not thought to be responsible for the lack of effects. Instead, these might have been due to the participants' overall moderately negative attitudes toward mental illness, and the 
ineffectiveness of the challenge procedure to influence attitudes that did not require much change.

When examining the trends in the case of challenge types on continuous verdict (See Figure 2), sentence length (See Figure 4) and on defendant likability (See Figure 6) outcomes are somewhat in the expected direction (see Schuller et al., 2009). Although differences were not significant, there were overall lower verdict ratings, lower sentences, and most positive impressions of the defendant associated with the reflective challenge group. Unexpectedly, trends suggest that the standard challenge may be a detrimental procedure as demonstrated by the harsher verdicts and sentences, and the least favorable impressions of the defendant. Although not significant, the reflective challenge might be a good potential correction for bias, whereby asking participants to reflect on how they may be influenced by MI makes it more relevant, and allows them to challenge their heuristics and correct for their biases. While the standard challenge questions their ability to remain impartial in a case involving mental illness, the reflective challenge tends to require participants to think and reflect on how they may be influenced by it. This need for detailed and more open-minded thinking and consideration about personal biases could reinforce the relevance of mental illness in the case. Although not significant, these trends highlight potential problems inherent in standard questioning procedures, and suggest that if a challenge is to be introduced into court, that a more reflective type might be more appropriate. While these suggestions may be premature based on the limited literature on the topic, Schuller et al. (2009) came to a similar conclusion and suggested that the current standard challenge procedure that the Canadian courts rely on to deal with the problem of bias may be an inadequate approach. 


\section{Limitations and Future Directions}

Inherent in jury research, a potential limitation of this study is the external validity. This study relied completely on an undergraduate student population, and therefore, the responses of this sample may not reflect those found in the general public. It is also possible that generational and gender differences would be found in the attitudes of a more age diverse and gender-balanced sample. As previously discussed, this study's design does not emulate real cases, wherein jurors are randomly selected from the public and deliberation takes place in decision-making. It is difficult to recreate the social psychological conditions of an actual verdict decision, particularly the responsibility and consequences of the decision weighing on the jury members, the drama of the courtroom events and the physical setting, the length of time actual trials require, and the dynamics the individuals who make up the juror group (Costanzo \& Costanzo, 1992). That being said, research does suggest that a simulation method, or the use of undergraduates, does not influence results in any detrimental way (Bornstein, 1999). The use of the Web for online studies has also shown to be comparable to in-lab research (Birmbaum, 2000; Buchanan \& Smith, 1999; Riva, Teruzzi, \& Anolli, 2003; Smith \& Leigh, 1997), and thus should not undermine the validity of this study. To further support the validity of this study, a comparison between online and in-lab methods was conducted, and results demonstrated justification for online research, with no significant differences between the online and in-lab groups in terms of verdict decisions, pre attitude scores, or post attitude scores. The implementation of additional safeguards (such as excluding those who finished the survey unrealistically quickly, as well as those who could not correctly identify details from the trial transcript) provides a defence against some of the doubts regarding the validity of the data collection method used.

The absence of a jury deliberation process could also be seen as a potentially limiting factor in this study's design (Bagby, Parker, Neil, Rector, \& Kalemba, 1994). Although it 
has been argued that deliberation processes are more realistic to real world court scenarios, literature has demonstrated that it is somewhat unnecessary in simulation methods because generally, individual jurors tend to already have their verdict decided before deliberation begins (Dillehay \& Nietzel, 1980). It could be debated that a deliberation process could be detrimental by making extra-legal factors, such as defendant MI, more salient. In contrast, deliberation could be a potential element for bias correction, whereby the open discussion among peers in deliberation of the trial outcomes in a case involving a defendant with mental illness may curb or reduce prejudicial effects. The salience and reflection aside, an issue within jury deliberation is the influential factor of social desirability where normative influences and pressures arise (Costanzo \& Costanzo, 1992). Participants may feel pressured by their peers or the circumstances and consequently may express their attitudes or verdict decisions in a manner that would be viewed more favorably by others. This social desirability bias with respect to attitudes and decisions in cases involving a defendant with a mental illness could somewhat undermine the respectable nature of the deliberation process. Future studies could examine the effects of deliberation processes in cases involving mental illness by evaluating attitudes and decisions made by individual jurors compared to juror panel decisions and attitudes after deliberation.

Another potential limitation lies within the materials used. It is unclear whether the mental illness manipulation was salient enough by having it mentioned in just one sentence of the entire transcript ("I like to jog at night because it is cooler and quieter. It helps to calm me down, and my psychiatrist recommended it to help me deal with my depression."). A total of $28.8 \%$ of students failed the manipulation check, and although $48 \%$ of these completed the survey in 20 minutes or less (suggesting that they did not take it seriously and did not take the time to read and answer the questions properly) it could be argued that the remaining $52 \%$ failed due to weak manipulation salience of the defendant's mental illness. 
When examining the failed manipulation checks in more detail, it could be suggested that, according to the failure rates, schizophrenia stood out more in the defendant's testimony compared to depression or $\mathrm{OCD}$, as it was correctly identified more often. This may speak to how commonplace these latter mental illnesses are in society today, thereby making them more likely to be overlooked or go unnoticed. The more frequent identification of schizophrenia may also relate to the media and its coverage of schizophrenia in criminal contexts - laypersons are exposed to news and television shows that highlight mental illness and criminality (particularly individuals with schizophrenia, and/or psychopathic traits) thereby making it more cognitively available and salient to participants reading the trial transcript. The manipulation check failure rates also demonstrate that participants were better able to correctly identify the defendant's mental illness when they were in the reflective challenge group compared to the no challenge or standard challenge groups. This could indicate that the reflective challenge possibly cued participants to thinking about mental illness in more detail, and in following, they read the trial transcript more attentively and were able to correctly identify the defendant's MI more often than the students who were in the no challenge or standard challenge conditions.

Future studies could compare a student and community sample to examine attitudes towards mental illness and its influence on legal decisions. As mentioned above, the use of an undergraduate sample does not allow for examining the effects of age and education level on decision making. Although difficult to conduct in terms of recruitment and resources, the investigation of jury deliberation methods in cases involving defendants with mental illness may also be worthwhile as there is no literature to date examining this topic. Similarly, the use of more detailed trial materials could also be instrumental to manipulate the salience of the mental illness. This could be achieved by mentioning the mental illness more than once, 
or in a different context, or possibly by including an expert witness psychiatrist's testimony about the defendant's mental illness.

Beyond methodological changes in future studies; research could also expand to include different or more specific types of mental illness such as bipolar, anorexia, or paranoid schizophrenia. It would be especially interesting to explore drug abuse and alcoholism, as the literature suggests that these addictions are highly stigmatized in society as they are commonly linked with unpredictability and dangerousness (Angermeyer \& Dietrich 2006; Link et al., 1999; Pescolido et al., 1999). Another future direction could be the use of different ways of measuring stigma. In the current study, the APWMI did not identify a precise type of mental illness. Stigma could be measured with scales or questionnaires that specifically label the mental illness or that discuss the mental illness in terms of symptoms and behavior.

For legal relevance, future studies could look at attitudes towards mental illness in comparing cases where NCRMD is a verdict option versus cases (like the one used here) where it is not. Research suggests that attitudes toward the insanity defence influences verdicts in such cases; however, past studies examining NCRMD or the insanity defence (see Bloechl, Vitacco, Neumann, \& Erickson, 2007; Crocker \& Kovera, 2010; Louden \& Skeem, 2007) have not accounted for attitudes towards mental illness, which could be the mitigating factor in verdict decisions. Bloechl et al. (2007) suggest that the public's negative attitudes toward the insanity defence are often based on prejudicial or heuristic beliefs regarding the mentally ill. That being said, no literature to date has examined whether the attitudes towards mental illness are the underlying reasons for the biases found towards the insanity defence. 


\section{Conclusion}

Angermeyer and Dietrich (2006) had called for more research looking at the relationship between attitudes about mental illness and actual behavior. Although there was a lack of findings, the present study contributes to the literature as it takes an important look at the influence of defendant mental illness on jurors and their verdict decisions. Stigma towards mental illness is evident in today's society with labels such as psycho, schizophrenic, addict, depressed, etc. The pejorative beliefs and attitudes towards mental illness and associated labels, which typically result in prejudice and discrimination towards individuals with mental illness, are in large part driven by the news and television dramas' depiction of mental illness. Due to the media's representation of mental illness and concomitant associations with violence and dangerousness, it was expected that mock-jurors would rely on the cognitive availability of these labels and stereotypes, and would consequently treat defendants with mental illness differently and more harshly than a defendant without MI. This idea was not supported by the data.

The Canadian legal system currently relies on the presumption that, as fellow citizens, jurors will serve as unbiased peers who will only be influenced by the evidence provided in court. That being said, extra-legal factors such as defendant characteristics have been identified in previous literature as influential elements in various juror decision-making scenarios. Controlling for and managing the impact of such factors is essential in ensuring a fair verdict by an impartial jury. Limited studies suggest that the use of a reflective challenge for cause procedure has the potential to be superior over standard procedures in reducing racial biases. Although results of the present study did not support the hypotheses that the defendant mental illness would be influential in verdict outcome, this study provides a preliminary look at issues surrounding the matter of stigma in the courtroom during trial proceedings, before individuals with mental illness can become inmates. While Mental 
Health Courts might be able to address stigma in some ways, these are limited to persons charged with minor offences, and as such these cases would not qualify to be tried by a jury of peers. Juror education or personal experience with mental illness may impact decisions, as well as the salience and relevance of the mental illness in the trial. Since there was modest stigma identified in mock-jurors at the beginning of the study, the challenge for cause procedures did not serve much purpose in reducing the already moderately negative stigma levels. However, this study does shed light on Canada's current challenge process and some issues underlying the standard procedure. Since it is currently estimated that $15-30 \%$ of inmates have a mental illness, attitudes towards mental illness need to be further explored and addressed in the areas of law and corrections. The present study is one of the few that has examined bias towards mental illness in juror decision-making, and there is a need for future research to explore the influence of defendant mental illness, particularly to understand the attitudes underlying the preconceptions about the NCRMD defence. 


\section{References}

Abel, C. (2003). Heuristics and problem solving. New Directions for Teaching and Learning, 95, 53-58.

Allport, G.W. (1954). The nature of prejudice. Reading, MA: Addison-Wesley. American Psychiatric Association. (2000). Diagnostic and statistical manual of mental disorders (4th ed. text rev.). Washington, DC: Author.

Angermeyer, M.C., Buyantugs, L., Kenzine, D.V., Matschinger, H. (2004). Effects of labelling on public attitudes towards people with schizophrenia: are there cultural differences? Acta Psychiatr Scand, 109, 420-425.

Angermeyer, M.C., \& Dietrich, S. (2006). Public beliefs about and attitudes towards people with mental illness: a review of population studies. Acta Psychiatr Scand, 113, 163179.

Bagby, R.M., Parker, J.D., Rector, N..A., \& Kalemba, V. (1994). Racial prejudice in the Canadian legal system: Juror decisions in a simulated rape trial. Law and Human Behavior, 3, 339-350.

Baron, J. (1985). Rationality and intelligence. Cambridge University Press.

Becker, H. S., (1963). Outsiders: Studies in the Sociology of Deviance. New York: Free Press.

Binder, R., \& McNiel, D. (1988). Effects of diagnosis and context on dangerousness. American Journal of Psychiatry, 145, 728-732.

Birnbaum, M.H. (Ed.). (2000). Psychological experiments on the Internet. San Diego: Academic Press. 
Bloechl, A.L., Vitacco, M.J., Neumann, C.S., \& Erickson, S.E. (2007). An empirical investigation of insanity defence attitudes: Exploring factors related to bias. International Journal of Law and Psychiatry, 30, 153-161.

Bodenhausen, G. V., \& Macrae, C. N. (1998).Stereotype activation and inhibition. In R. S. Wyer, Jr. (Ed.), Stereotype activation and inhibition: Advances in social cognition, 11, 1-52. Mahwah, NJ: Erlbaum.

Bornstein, B. H. (1999). The ecological validity of jury simulations: Is the jury still out? Law and Human Behavior, 23, 75-91.

Bornstein, B., \& Rajki, M. (1994). Extra-legal factors and product liability: The influence of mock jurors' demographic characteristics and intuitions about the cause of an injury. Behavioral Sciences \& the Law, 12, 127-1 47.

Brewer, T.W. (2004). Race and jurors' receptivity to mitigation in capital cases: The effect of jurors', defendants', and victims' race in combination. Law and Human Behaviour, 28, 529-545.

Buchanan, T., \& Smith, J.L. (1999). Using the Internet for psychological research: Personality testing on the World-Wide Web. British Journal of Psychology, 90, 125144.

Buckley, P.F., Miller, B.J., Lehrer, D.S., \& Castle, D.J. (2009). Psychiatric comorbidities and schizophrenia. Schizophrenia Bulletin, 35, 383-402.

Campitelli, G., \& Labollita, M. (2010). Correlations of cognitive reflection with judgments and choices. Judgments and Decision Making, 5, 182-192.

Canadian Charter of Rights and Freedoms, PART I OF THE CONSTITUTION ACT, 1982.

Canadian Institute for Health Information (2008). Improving the Health of Canadians: Mental Health, Delinquency and Criminal Activity. Ottawa, Canadian Institute for Health Information. 
Cacioppo, J. T., Petty, R. E., \& Kao, C. F. (1984). The efficient assessment of need for cognition. Journal of Personality Assessment, 48, 306-307.

Colwell, L.H. (2005). Cognitive heuristics in the context of legal decision-making. American Journal of Forensic Psychology, 23, 17-41.

Corrigan, P.W., River, L.P., Lundin, R.K., Wasowski, K.U., Campion, J., Mathisen, J., Goldstein, H., Bergman, M., \& Gagnon, C. (2000). Stigmatizing attributions about mental illness. Journal of Community Psychology, 28, 91-102.

Corrigan, P.W., \& Watson, A.C. (2002).The paradox of self-stigma and mental illness. Clinical Psychology: Science and Practice, 9, 35-53.

Costanzo, M., \& Costanzo, S. (1992). Jury decision making in the capital punishment phase: Legal assumptions, empirical findings, and a research agenda. Law and Human Behavior, 16, 185-201.

Crisp, A., Gelder, M.G., Rix, S., Meltzer, H.I., \& Rowlands, O.J. (2000). Stigmatization of people with mental illnesses. British Journal of Psychiatry, 177, 4-7.

Crocker, C.B., \& Kovera, M.B. (2010). The effects of rehabilitative voir dire on juror bias and decision making. Law and Human Behaviour, 34, 212-226.

CSC launches a comprehensive mental health strategy. Correctional Service Canada: Let's Talk, 2008, Vol 34(1). Retrieved January $4^{\text {th }}, 2011$, from: http://www.csc-scc.gc.ca/text/pblct/lt-en/2007/32-1/2-eng.shtml

Dallal, G. (2005). The analysis of pre-test/post-test experiments. Retrieved May $18^{\text {th }}, 2011$, from: http://www.jerrydallal.com/LHSP/prepost.htm

Dietrich, S., Herider, D., Matschinger, H., Angermeyer, M.C (2006). Influence of newspaper reporting on adolescents' attitudes toward people with mental illness. $C M H$ 
Dillehay, R. C., \& Nietzel, M. T. (1980). Constructing a science of jury behavior. In L. Wheeler (Ed.), Review of personality and social psychology (pp. 246-264). Beverly Hills, CA: Sage.

Dixon, C.R., (1967). Courses in psychology and student' attitudes towards mental illness. Psychological Reports, 20, 50.

Eagly, A.H., \& Chaiken, S. (1998). Attitude structure and function. In D.T. Gilbert, S.T. Fiske, \& G. Lindzey (Eds.), The handbook of social psychology $\left(4^{\text {th }}\right.$ ed. Vol. 1 , pp.269-322). New York: McGraw Hill.

Eberhardt, J.L., Davies, P.G., Purdie-Vaughns, V.J., Johnson, S.L. (2006). Looking deathworthy: Perceived stereotypicality of black defendants predicts capitalsentencing outcomes. Psychological Science, 17, 383-386.

Eberhardt, J.L., Goff, P.A., Purdie, V.J., \& Davies, P.G. (2004). Seeing black: Race, crime, and visual processing. Journal of Personality and Social Psychology, 87, 876-893.

Eisenberg, T., Garvey, S.P, \& Wells, M.T. (2001). Forecasting life and death: Juror race, religion, and attitudes toward the death penalty. Journal of Legal Studies, 30, $277-$ 311.

Evans, J. S. (1984). Heuristics and analytic processes in reasoning. British Journal of Psychology, 75, 451-468.

Felson, R. B. (1985). Reflected appraisal and the development of self. Social Psychology Quarterly, 48, 71-78.

Fiske, S.T. (1993). Controlling other people: The impact of power on stereotyping. American Psychologist, 48, 621-628.

Fiske, S.T. (2011). Envy up, scorn down: How status divides us. Honorary President's Address given at the $72^{\text {nd }}$ Annual Canadian Psychological Association Convention (June, 2011), Toronto, ON, Canada. 
Fiske, S.T. (1998). Stereotyping, prejudice, and discrimination. In D.T. Gilbert, S.T. Fiske, \& G. Lindzey (Eds.), The handbook of social psychology $\left(4^{\text {th }}\right.$ ed. Vol. 2, pp.357-411). New York: McGraw Hill.

Fiske, S.T., \& Neuberg, S.L. (1990). A continuum of impression formation, from categorybased to individuating processes: Influence of information and motivation on attention and interpretation. In M.P. Zanna (Ed.), Advances in experimental social psychology (Vol. 23, pp. 1-74). New York: Academic.

Foley, L.A., \& Chamblin, M.H. (1982). The effect of race and personality on mock jurors' decisions. The Journal of Psychology, 112, 47-51.

Folsom, J. (2010). Correctional Service Canada Health Services: Psychology in prisons. Retrieved August $6^{\text {th }}, 2012$, from: http://www.csc-scc.gc.ca/text/hlth/pip-2010-eng.shtml

ForsterLee, R., ForsterLee, L., Horowitz, I.A., \& King, E. (2006). The effect of defendant race, victim race, and juror gender on evidence processing in a murder trial. Behavioural Sciences \& the Law, 24, 179-198.

Francis, C., Pirkis, J., Dunt, D., Blood, R.W. (2001). Mental health and illness in the media: A review of the literature. Commonwealth Department of Health and Ageing Canberra.

Gigerenzer, G (2008). Why heuristics work. Perspectives on Psychological Science, 3, 20 29. Goffman, E. (1963). Stigma: Notes of the Management of a Spoiled Identity. Englewood Cliffs, NJ: Prentice Hall.

Gollwitzer, P.M., \& Schaal, B. (1998). Metacognition in action: The importance of implementation intentions. Personality and Social Psychology Review, 2, 124-136. 
Gordon, R.A., Bindrim, T.A., McNicholas, M.L., \& Walden, T.L. (1988). Perception of blue-collar and white-collar crime: The effect of defendant race on simulated juror decisions. The Journal of Social Psychology, 128, 191-197.

Guy, L.S., \& Edens, J.F. (2003). Juror decision-making in a mock sexually violentpredator trial: Gender differences in the impact of divergent types of expert testimony. Behavioural Sciences \& the Law, 21, 215-237.

Guy, L.S., \& Edens, J.F. (2006). Gender differences in attitudes toward psychopathic sexual offenders. Behavioural Sciences \& the Law, 24, 65-8

Hamilton, D.L., \& Gifford, R.K. (1976). Illusory correlation and the maintenance of stereotypic beliefs. Journal of Personality and Social Psychology, 39, 832-845.

Hans, V. (1986). An analysis of public attitudes toward the insanity defense. Criminology, $24,383-414$

Jones, M. (1997). Preventing the application of stereotypic biases in the courtroom: The role of detailed testimony. Journal of Applied Social Psychology, 27, 1767-1784.

Kendra, M.S., Cattaneo, L.B., \& Mohr, J.J. (2012). Teaching abnormal psychology to improve attitudes towards mental illness and help-seeking. Teaching of Psychology, $39,57-61$.

Klassen, D., \& O'Connor, W. (1988a). A prospective study of predictors of violence in adult male mental patients. Law and Human Behavior, 12, 143-158.

Kobau, R., Dilorio, C., \& Chapman, D. (2010). Attitudes about mental illness and its treatment: Validation of a generic scale for public health surveillance of mental illness associated stigma. Community Mental Health Journal, 46, 164-176.

Koskie, J., Hendrick, K., \& Kelly, D. (2010). The substandard treatment of mentally ill inmates is criminal: Experts. Canadian Mental Health Association. News Release, 
November $4^{\text {th }}, 2010$. Retrieved on December $6^{\text {th }}, 2010$, from:

http://www.cmha.ca/bins/content page.asp?cid $=6-20-21-965-773$

Kruglanski, A.W., \& Freund, T. (1983). The freezing and unfreezing of lay-inferences:

Effects of impressional primacy, ethnic stereotyping, and numerical anchoring. Journal of Experimental Social Psychology, 19, 448-468.

Latimer, J. \& Lawrence, A. (2006). The review board systems in Canada: An overview of results from the mentally disordered accused data collection study. Report rr06-1e.

Ottawa, Justice Canada, Research and Statistics Division. Retrieved on August $6^{\text {th }}, 2012$, from: http://www.justice.gc.ca/eng/pi/rs/rep-rap/2006/rr06 1/rr06 1.pdf

LeBel, T.B., Burnett, R., Maruna, S., \& Bushway, S. (2008). The 'chicken and egg' of subjective and social factors in desistance from crime. European Journal of Criminology, 5, 131-159.

Levett, L.M., \& Kovera, M.B. (2008). The effectiveness of opposing expert witnesses for educating jurors about unreliable expert evidence. Law and Human Behavior, 32, $363-374$.

Link, B.G., \& Cullen, F.T. (1986). Contact with the mentally ill and perceptions of how dangerous they are. Journal of Health and Social Behavior, 27, 289-303.

Link, B.G., Cullen, F.T., Frank, J., \& Wozniak, J. (1987). The social rejection of ex-mental patients: understanding why labels matter. American Journal of Sociology, 92, 14611500.

Link, B.G., Cullen, F.T., Stuening, E., Shrout, P, \& Dohrenwend, B.P. (1989). A modified labelling theory approach in the area of mental disorders: an empirical assessment. American Sociological Review, 54, 100-123.

Link, B.G., \& Phelan, J.C. (2001). Conceptualizing stigma. Annual Review of Sociology, 27, 363-385. 
Link, B.G., Phelan, J.C., Bresnahan, M., Stueve, A., \& Pescosolido, B.A. (1999). Public conceptions of mental illness: labels, causes, dangerousness, and social distance. American Journal of Public Health, 89, 1328-1333.

Lord, C.G, Lepper, M.R., \& Mackie, D. (1984). Attitude prototypes as determinants of attitude-behaviour consistency. Journal of Personality and Social Psychology, 46, 1254-1266.

Louden, J.E., \& Skeem, J.L. (2007), Constructing Insanity: Jurors' prototypes, attitudes and legal decision-making. Behavioural Sciences \& the Law, 25, 449-470.

Macrae, C.N., Hewstone, M., \& Griffiths, R.G. (1993). Processing load and memory for stereotype-based information. European Journal of Social Psychology, 23, 77-87.

Maio, G.R., Olson, J.M., Bernard, M.M, \& Luke, M.A. (2003). Ideologies, values, attitudes, and behavior. In J. Delamater (Ed.), Handbook of social psychology (pp. 283-308). New York: Kluwer-Plenum.

Mak, W.W.S., Poon, C.Y.M., Pun, L.Y.K., \& Cheung, S.F. (2007). Meta-analysis of stigma and mental health. Social Science and Medicine, 65, 245-261.

Mayer, R. (1983). Thinking, Problem Solving, Cognition. New York: Freeman.

Mazzella, R., \& Feingold, A. (1994). The effects of physical attractiveness, race, socioeconomic status, and gender of defendants and victims on judgments of mock jurors: A meta-analysis. Journal of Applied Social Psychology, 24, 1315-1344.

McGuire, J. (2000). Can the criminal law ever be therapeutic? Behavioral Sciences and the Law, 18, 413-426.

McGraw, S. L., \& Foley, L. A. (2000). Perceptions of insanity based on occupation of defendant and seriousness of crime. Psychological Reports, 86, 163-174. 
McNamara, K., Vattano, F., \& Viney, W. (1993). Verdict, sentencing, and certainty as a function of sex of juror and amount of evidence in a simulated rape trial. Psychological Reports, 72, 575-583.

Mitchell, T.L., Haw, R.M., Pfeifer, J.E., \& Meissner, C.A. (2005). Racial bias in mock juror decision-making: A meta-analytic review of defendant treatment. Law and Human Behavior, 29, 621-637.

Monahan, J. (1984). The prediction of violent behavior: Toward a second generation of theory and policy. American Journal of Psychiatry, 140, 10-15.

Monahan, J. (1988). Risk assessment of violence among the mentally disordered: Generating useful knowledge. International Journal of Law and Psychiatry, 11, 249-257.

Monahan, J. (2002). The MacArthur studies of violence risk. Criminal Behavior and Mental Health, 12, 67-72.

Mossière, A.M., \& Dalby, J.T. (2008). The influence of gender and age in mock juror decision-making. Europe's Journal of Psychology, 4.

Nikonova, O., \& Ogloff, J.R.P. (2005). Mock jurors' perceptions of child witnesses: The impact of judicial warning. Canadian Journal of Behavioural Science, 37, 1-19.

O’Neil, K. M., Patry, M. W., \& Penrod, S. D. (2004). Exploring the effects of attitudes toward the death penalty on capital sentencing verdict. Psychology, Public Policy, and Law, 10, 443-470.

Pennington, N., \& Hastie, R. (1986).Evidence evaluation in complex decision making. Journal of Personality and Social Psychology, 51, 242-258.

Pescosolido, B. A., Monahan, J., Link, B. G., Stueve, A., \& Kikuzawa, S. (1999). The public's view of the competence, dangerousness, and need for legal coercion of persons with mental health problems. American Journal of Public Health, 89, 13391345. 
Petty, R.E., \& Wegener, D.T. (1998). Attitude change: Multiple roles for persuasion variables. In D.T. Gilbert, S.T. Fiske, \& G. Lindzey (Eds.), The handbook of social psychology (4 $4^{\text {th }}$ ed. Vol. 1, pp.323-390). New York: McGraw Hill.

Phelan, J.C., \& Link, B.G. (2004). Fear of people with mental illnesses: The role of personal and impersonal contact and exposure to threat or harm. Journal of Health and Social Behaviour, 45, 68-80.

Pozzulo, J.D., Dempsey, J., Maeder, E., \& Allen, L. (2010). The effects of victim gender, defendant gender, and defendant age on juror decision making. Criminal Justice and Behaviour, 37, 47-63.

Preliminary, Mid-Trial, and Final Instructions. Canadian Judicial Council. Retrieved on December $6^{\text {th }}, 2010$, from:

http://www.cjc-ccm.gc.ca/cmslib/general/lawyers ji PrelimMidFinalInstructions en.pdf Regina v. Parks (1993) 15 O.R. (3d) 324 (C.A.).

Regina v. Williams (1998) 1 S.C.R. 1128, S.C.J. 49.

Riva, G., Truzzi, T., \& Anolli, L (2003). The use of the internet in psychological research: Comparison of online and offline questionnaires. Cyber Psychology and Behavior, 6 , 73-80.

Rose, G.V. (2001). An introduction to law and the Canadian legal system. In R.A. Schuller \& J.R.P. Ogloff (Eds.), Introduction to Psychology and Law, 2, 29-56. Toronto, Ontario: University of Toronto Press.

Rothbart, M. (1981). Memory processes and social beliefs. In D.L. Hamilton (Ed.), Cognitive processes in stereotyping and intergroup behaviour (pp. 145-181). Hillsdale, NJ: Erlbaum.

Rubin, Z., \& Peplau, L.A. (1975). Who believes in a just world? Journal of Social Issues, $31,68-88$ 
Rüsch, N., Angermeyer, M.C., \& Corrigan, P.W. (2005). Mental illness stigma: Concepts, consequences, and initiatives to reduce stigma. European Psychiatry 20, 529-539.

Schomerus, G., Holzinger, A., Matschinger, H., Lucht, M., \& Angermeyer, M. (2010). Public attitudes towards alcohol dependence an overview. Psychiatrische Praxis, 37, $111-118$

Schuller, R., Kazoleas, V., Kawakami, K. (2009). The impact of prejudice screening procedures on racial bias in the courtroom. Law \& Human Behaviour, 33, 320-328.

Schuller, R.A., \& Yarmey, M. (2001). The jury: Deciding guilt and innocence. In R.A. Schuller \& J.R.P. Ogloff (Eds.), Introduction to Psychology and Law, 6, 157-187. Toronto, Ontario: University of Toronto Press.

Schutte, J. W., \& Hosch, H. M. (1997). Gender differences in sexual assault verdicts: A meta-analysis. Journal of Social Behaviour and Personality, 12, 759-772.

Serin, R.C., Lloyd, C.D., \& Hanby, L.J. (2010). Enhancing offender re-entry: An integrated model of enhancing offender re-entry. European Journal of Probation, 2, 53-75.

Sinha, M. (2009). An investigation into the feasibility of collecting data on the involvement of adults and youth with mental health issues in the criminal justice system. Retrieved on August $6^{\text {th }}, 2012$, from Statistics Canada: Crime and Justice Research Paper Series, 16: http://www.statcan.gc.ca/pub/85-561-m/85-561-m2009016-eng.pdf

Skeem, J.L., \& Golding, S.L. (2001). Describing jurors' personal conceptions of insanity and their relationship to case judgements. Psychology, Public Policy, and Law, 7, 561621.

Skeem, J.L., Louden, J.E., \& Evans, J. (2004). Venirepersons's attitudes toward the insanity defense: Developing, refining, and validating a scale. Law and Human Behaviour, $28,623-648$ 
Smith, M.A., \& Leigh, B. (1997). Virtual subjects: Using the Internet as an alternative source of subjects and research environment. Behavior Research Methods, Instruments \& Computers, 29, 496-505.

Sommers, S.R., \& Ellsworth, P.C. (2000). Race in the courtroom: Perceptions of guilt and dispositional attributions. Personality \& Social Psychology Bulletin, 26, 13671379.

Sommers, S.R., \& Ellsworth, P.C. (2001). White juror bias: An investigation of prejudice against Black defendants in the American courtroom. Psychology, Public Policy, and Law. 7, 201-229.

Stangor, C. (1988). Stereotype accessibility and information processing. Personality and Social Psychology Bulletin, 14, 694-708.

Stangor, C., \& Ford, T.E. (1992). Accuracy and expectancy-confirming processing orientations and the development of stereotypes and prejudice. In W. Stroebe \& M. Hewstone (Eds.), European review of social psychology (Vol. 3, pp. 57-89). New York: Wiley.

Stuart, H. (2003). Violence and mental illness: An overview. World Psychiatry, 2, 121-124.

Tellier, C., \& Felizardo, V. (2011). Out of sight, back into mind: Federal offenders with mental disorders preparing for release into the community. Presentation to the Canadian Criminal Justice Association Pan-Canadian Congress (October, 2011). Retrieved on August $4^{\text {th }}, 2012$, from: www.ccja-acjp.ca/cong2011/2011-G.pptx

Tversky, A., \& Kahneman, D. (1973). Availability: A heuristic for judging frequency and probability. Cognitive Psychology, 5, 207-232.

Tversky, A., \& Kahneman, D. (1974). Judgment under uncertainty: Heuristics and biases. Science, 185, 1124-1131. 
Vidmar, N. (1997). Pre-trial prejudice and the presumption of guilt in sex abuse trials. Law and Human Behavior, 21, 5-25.

Vidmar, N., \& Hans, V. P. (2007). American juries, the verdict. Amherst, NY: Prometheus Books.

Vidmar, N., \& Schuller, R.A. (2001). The jury: Selecting twelve impartial peers. In R.A. Schuller \& J.R.P. Ogloff (Eds.), Introduction to Psychology and Law, 5, 126-156. Toronto, Ontario: University of Toronto Press.

Wilson, C., Nairn, R., Coverdale, J., \& Panapa, A. (1999). Mental illness depictions in prime-time dramas: Identifying the discursive resources. Australian and New Zealand Journal of Psychiatry, 33, 232-239.

Yeap, R. (2008). Common misconceptions and attitudes towards psychology and mental health: A Malaysian context. Unpublished PhD Dissertation. Retrieved on April $19^{\text {th }}$, 2012, from: http://dspace.fsktm.um.edu.my/handle/1812/479

Zanna, M. P., \& Rempel, J. K. (1988). Attitudes: A new look at an old concept. In D. BarTal \& A. W. Kruglanski (Eds.), The social psychology of knowledge (pp. 315-334), Cambridge, England: Cambridge University Press. 


\section{APPENDIX A: EXAMPLE of SONA RECRUITMENT NOTICE}

Study Name: An Analysis of Juror Decision-Making in a Criminal Trial

Description: This study asks participants to act as jurors in a criminal trial. Participants will determine the verdict in a case, and complete a questionnaire. Warning: Participant might get upset from reading about a criminal case.

Eligibility Requirements: We are looking for students who are Canadian citizens over the age of 18 , who have a high proficiency in the English language, and who have no prior convictions.

Duration and Locale: $45 \mathrm{~min}$ - Online.

Compensation: You will receive $0.5 \%$ towards a psychology or criminology course for your time and participation.

Researchers: Annik Mossière (Principal Investigator); Dr. Evelyn Maeder (Faculty Sponsor)

Email: amossier@connect.carleton.ca

This study has received clearance by the Carleton University Psychology Research Ethics Board (Reference \#11-045). 


\section{Carleton \\ $U N \| V E R S I T Y$}

$\begin{array}{ll}\text { Project Title: } & \text { An Analysis of Juror Decision-Making in a Criminal Trial } \\ \text { Investigator: } & \begin{array}{l}\text { Annik Mossière } \\ \text { Department of Psychology } \\ \text { Carleton University } \\ \text { amossier@connect.carleton.ca }\end{array} \\ & \begin{array}{l}\text { Dr. Evelyn Maeder } \\ \text { Department of Psychology \& Department of Criminology } \\ \text { Carleton University } \\ \text { (613) 520-2600 x } 2421\end{array} \\ & \text { Evelyn Maeder@carleton.ca } \\ & \text { Online }\end{array}$

This consent form, a copy of which has been given to you, is only part of the process of informed consent. If you want more details about something mentioned here, or information not included here, you should feel free to ask. Your signature on this form indicates that you 1) understand to your satisfaction the information provided to you about your participation in this research project, and 2) agree to participate as a research subject.

Please take the time to read this carefully and to understand any accompanying information.

This study has been approved by the Carleton University Ethics Committee for Psychological Research. 


\section{Purpose of the Study}

The purpose of this study is to investigate the decisions made by mock jurors in a criminal trial.

\section{What Will I Be Asked To Do?}

You will begin by completing a questionnaire about various legal topics. In this study, you are a mock jury member. A mock trial is in session and you will start by receiving juror instructions, then you will read a short transcript from the trial. You will then be asked two questions: the first regarding the defendant's guilt and the second regarding sentence length. Finally, you will be asked to complete a questionnaire and provide some demographic information. This study will take you approximately $45 \mathrm{~min}$ to complete, and you will receive 0.5 credits for your time. Your participation is voluntary, and therefore you are free to withdraw from the experiment at any time by clicking the Exit button at the top of the page or leave questions unanswered without penalty.

\section{What Type Of Personal Information Will Be Collected?}

Should you agree to participate, you will be asked to provide your gender, age, education, and occupation. In no way will this information, or any of your responses to the questionnaire, be linked back to you. We ensure that your internet IP address will not be collected in Survey Monkey. In order to ensure complete confidentiality, arbitrary participant numbers will be assigned to each questionnaire. You will not be asked to include your name or other identifying information on any of the test materials.

\section{Are there Risks or Benefits if I Participate?}

The description of the crime may upset some individuals. Although it is not anticipated that this will be a problem for most participants, it is important that you are aware of this 
possibility so you can choose to withdraw from the study now or at any other point without penalty.

In addition, if you experience distress as a result of your participation in this study, Carleton University also offers confidential counselling. Carleton University Health and Counselling Services are located in the Carleton Technology \& Training Centre, Room 2600. Call 613520-6674, or refer to their website for more information: http://www2.carleton.ca/health/counselling-services/

\section{What Happens to the Information I Provide?}

All information collected during this study will be kept anonymous and confidential, and questionnaires will be kept in a locked cabinet in the Legal Decision-Making Lab. Only the experimenter and her supervisor will have access to this information. The anonymous data (i.e. test questionnaire) and the consent forms will be stored for two years, at which time, it will be permanently destroyed.

In exchange for your time, I hope that you gain some insight and knowledge into the current research that is taking place within the field of psychology and law.

By registering to participate in this research study using the Sona Systems Research Participation System, you will receive 0.5 credits that will go towards your grade for one of your applicable psychology courses.

If you have any further questions or want clarification regarding this research and/or your participation, please contact: 
Annik Mossière

amossier@connect.carleton.ca

Dr. Evelyn Maeder

(613) $520-2600 \times 2421$

Evelyn_Maeder@carleton.ca

If you have any questions or concerns about the way you've been treated as a participant, please contact Dr. Anne Bowker, Chair of Department of Psychology, Carleton University, at 613-520-2600 ext. 8218, anne bowker@carleton.ca, or Monique Sénéchal, the Chair of the Psychology Research Ethics Board, at Ext. 1155, monique senechal@carleton.ca

I have read the above form and understand the conditions of my participation. By checking this box, I'm indicating that I agree to participate in this study.

I have read the above form and understand the conditions of my participation. By checking this box, I'm indicating that I disagree to participate in this study. 


\section{APPENDIX C: ATTITUDES AND FILLERS QUESTIONNAIRE}

Please pay attention to the answer choices, as they vary throughout this questionnaire.

1. A judge should have the right to sentence a defendant to death, even if the jury has recommended life in prison.

$\begin{array}{lllll}1 & 2 & 3 & 4 & 5\end{array}$

$\begin{array}{lll}\text { Strongly Agree } & \text { Undecided } & \text { Strongly Disagree }\end{array}$

2. Federal government doesn't help individuals in society who are negatively affected by social problems enough.
1
2
3
4
5

Strongly Agree

Neutral

Strongly Disagree

3. Appointed judges are more competent than elected judges.

$\begin{array}{lllll}1 & 2 & 3 & 4 & 5\end{array}$

Strongly Agree

Strongly Disagree

4. A suspect who runs from the police most probably committed the crime.

$\begin{array}{lllll}1 & 2 & 3 & 4 & 5\end{array}$

Strongly Agree $\quad$ Strongly Disagree

*5. I believe a person with mental illness is unpredictable.

$\begin{array}{llllll}1 & 2 & 3 & 4 & 5\end{array}$

Strongly Disagree $\quad$ Strongly Agree 
JUROR STIGMA TOWARDS MENTAL ILLNESS

6. I like tasks that require little thought once I've learned them.

$\begin{array}{cccccccc}1 & 2 & 3 & 4 & 5 & 6 & 7 & 8 \\ \text { Very Strongly Agree } & & & \text { Neutral } & & \text { Very Strongly Disagree }\end{array}$

7. I've found that a person rarely deserves the reputation he or she has.

$\begin{array}{llllll}1 & 2 & 3 & 4 & 5 & 6\end{array}$

Strongly Disagree Disagree Somewhat Agree Somewhat Strongly Disagree

8. It is a common occurrence for a guilty person to get off free in Canadian courts.
1
2
3
4
5
6

Strongly Disagree

Disagree Somewhat

Agree Somewhat

Strongly Disagree

9. A vote for the death penalty in some cases may be due to discrimination against a defendant who is a minority.
1
2
3
4
5

Strongly Agree $\quad$ Undecided Strongly Disagree

10. Most politicians are really as honest as humanly possible.
1
2
3
4
5

Strongly Agree

Strongly Disagree

*11. I believe a person with mental illness could pull himself/herself together if he/she wanted.
1
2
3
4
5

Strongly Disagree

Strongly Agree 
12. I try to anticipate and avoid situations where there is likely a chance I will have to think in depth about something.

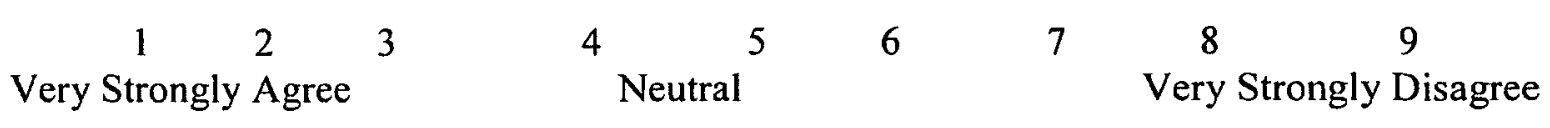

13. The insanity defence is a necessary element in our legal system.
1
2
3
4
5
$\begin{array}{ll}6 & 7\end{array}$

Strongly Disagree

Neutral

Strongly Agree

14. Too often jurors hesitate to convict someone who is guilty out of pure sympathy.
1
2
3
4
5

Strongly Agree

Strongly Disagree

15. For serious crimes like murder, a defendant should be found guilty if there is a $90 \%$ chance that he committed the crime.
1
2
3
4
5

Strongly Agree

Strongly Disagree

16. People who meet with misfortune have often brought it on themselves.

1

2

3

Disagree Somewhat

Agree Somewhat

6

Strongly Disagree

17. Defence lawyers don't really care about guilt or innocence; they are just in business to make money.$$
1
$$

3

Strongly Agree
5

45

Strongly Disagree

* 18. I believe a person with mental illness can be as successful at work as others.

$\begin{array}{ccccc}1 & 2 & 3 & 4 & 5 \\ \text { Strongly Disagree } & & & & \text { Strongly Agree }\end{array}$


19. Hypocrisy is on the increase in society.
1
2
3
4 5

Strongly Agree

Strongly Disagree

20. With slick attorneys and a sad story, any criminal can use the insanity defence to finagle his way to freedom.
1
2
3
4
5
67

Strongly Disagree

Neutral

Strongly Agree

21. In almost any business or profession, people who do their job well rise to the top.

1

2 3

4

Disagree Somewhat

Agree Somewhat

5

6

Strongly Disagree

(1)

22. It is rare for an innocent person to be wrongly sent to jail.

1

2

3

Disagree Somewhat

Strongly Disagree

*23. Treatment can help people with mental illness lead normal lives.

1

2

3

4

5

Strongly Disagree
4

Agree Somewhat
5

6

Strongly Disagree

24. The idea of relying on thought to make my way to the top appeals to me.

$\begin{array}{cc}1 & 2 \\ \text { Very Strongly } & \text { Agree }\end{array}$

3
$4 \quad 5 \quad 6$ Neutral

Strongly Agree 
25. Generally, the police make an arrest only when they are sure about who committed the crime.
1
2
3
4
5

Strongly Agree

Strongly Disagree

26. Circumstantial evidence is too weak to use in court.
1
2
3
4
5

Strongly Agree

Strongly Disagree

*27. I believe a person with mental illness can eventually recover.
1
2
3
4
5

Strongly Disagree

Strongly Agree

28. I usually end up deliberating about issues even when they do not affect me personally.

$\begin{array}{cccccccc}1 & 2 & 3 & 4 & 5 & 6 & 7 & 8 \\ \text { Very Strongly Agree } & & \text { Neutral } & & & \text { Very Strongly Disagree }\end{array}$

29. The defendant is often a victim of his own bad reputation.
1
2
3
4
5

Strongly Agree

Strongly Disagree

30. I believe that we should punish a person for a criminal act only if he understood the act as evil and then freely chose to do it.
1
2
3
4
5
6
7

Strongly Disagree

Neutral

Strongly Agree 
31. By and large, people deserve what they get.

$\begin{array}{llllll}1 & 2 & 3 & 4 & 5 & 6\end{array}$

Strongly Disagree Disagree Somewhat Agree Somewhat Strongly Disagree

*32. I believe a person with mental illness is hard to talk with.

$\begin{array}{lllll}1 & 2 & 3 & 4 & 5\end{array}$
Strongly Disagree
Strongly Agree

33. Extenuating circumstances should not be considered - if a person commits a crime, then that person should be punished.
1
2
3
4
5

Strongly Agree

Strongly Disagree

34. In professional sports, many fouls and infractions never get called by the referee.

$\begin{array}{lllllll}1 & 2 & 3 & 4 & 5 & 6\end{array}$

Strongly Disagree Disagree Somewhat Agree Somewhat Strongly Disagree

35. If a majority of the evidence - but not all of it - suggests that the defendant committed the crime, the jury should vote not guilty.
1
2
3
4
5

Strongly Agree

Strongly Disagree 
*36. I believe a person with mental illness has only himself/herself to blame for his/her condition
1
2
3
4
5

Strongly Disagree

Strongly Agree

37. I like to have the responsibility of handling a situation that requires a lot of thinking.

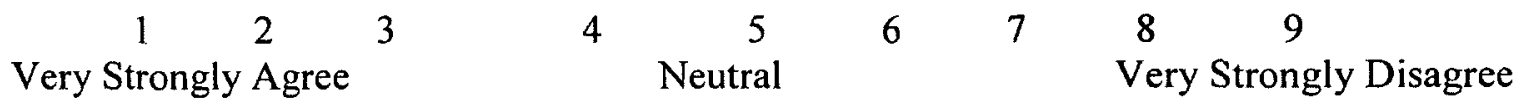

38. If the defendant committed a victimless crime, like gambling or possession of marijuana, he should never be convicted.
1
2
3
4
5

Strongly Agree

Strongly Disagree

*39. People are generally caring and sympathetic to people with mental illness.
1
2
3
4
5

Strongly Disagree

Strongly Agree

40. Careful drivers are just as likely to get hurt in traffic accidents as careless ones.

$\begin{array}{llllll}1 & 2 & 3 & 4 & 5 & 6\end{array}$

Strongly Disagree Disagree Somewhat Agree Somewhat Strongly Disagree 
*41. I believe a person with mental illness is a danger to others.
1
2
3
4
5

Strongly Disagree

Strongly Agree

42. I really enjoy a task that involves coming up with new solutions to problems.

$\begin{array}{ccccccccc}1 & 2 & 3 & 4 & 5 & 6 & 7 & 8 & 9 \\ \text { Very Strongly Agree } & & & & \text { Neutral } & & & \text { Very Strongly Disagree }\end{array}$

43. The insanity defence should be abolished.
1
2
3
4
5
6
7

Strongly Disagree

Neutral

Strongly Agree

*44. I believe a person with mental illness would improve if given treatment and support.
1
2
3
4
5

Strongly Disagree

Strongly Agree

45. Sometimes individuals in society who are negatively affected by social problems don't try hard enough.
1
2
3
4
5

Strongly Agree

Neutral

Strongly Disagree

46. It is necessary to permit the death penalty in order to reduce the murder rate.
1
2
3
4
5

Strongly Agree

Undecided

Strongly Disagree 
47. I prefer to think about small, daily projects to long-term ones.

$\begin{array}{lllllllll}1 & 2 & 3 & 4 & 5 & 6 & 7 & 8 & 9\end{array}$

Very Strongly Agree Neutral $\quad$ Very Strongly Disagree

$* 48$. I believe a person with mental illness feels the way we all do at times

$\begin{array}{lllll}1 & 2 & 3 & 4 & 5\end{array}$

Strongly Disagree $\quad$ Strongly Agree

49. I do not believe that the insanity defence sends a message to average criminals that they can escape punishment.
1
2
3
4
5
6

Strongly Disagree

Neutral

Strongly Agree

50. I feel relief rather than satisfaction after completing a task that required a lot of mental effort.

$\begin{array}{lllllllll}1 & 2 & 3 & 4 & 5 & 6 & 7 & 8 & 9\end{array}$

Very Strongly Agree Neutral Very Strongly Disagree 


\section{APPENDIX D: JUROR PRE-TRIAL/CHALLENGE QUESTIONS}

The purpose of this study is to investigate decisions made by mock jurors and in a criminal trial.

$\rightarrow$ After being informed of the charge against the defendant (Benjamin Smith is being charged with Robbery), participants will be asked one of the following sets of questions.

Benjamin Smith is being charged with Robbery.

No Challenge/No Pre-Trial Questioning

Can you judge this case solely on the evidence and the instructions from the judge? Yes No

\section{Standard Close-Ended Challenge for Cause}

Do you think that your ability to judge the case the evidence in this case without bias, prejudice, or sympathy would be affected by the fact that the person charged has a mental illness?

Yes No

Can you judge this case solely on the evidence and the instructions from the judge?

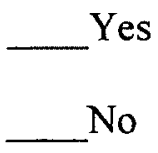

How confident are you in your ability to remain impartial in this case?
1 Not at all confident)

2
3
4
5
6
7 (Completely Confident) 


\section{Reflective Challenge for Cause}

How might your ability to judge the evidence in the case be affected by the fact that the defendant has a mental illness?

Do you think that your ability to judge the case the evidence in this case without bias, prejudice, or sympathy would be affected by the fact that the person charged has a mental illness?

Yes No

Can you judge this case solely on the evidence and the instructions from the judge? Yes No

How confident are you in your ability to remain impartial in this case?

1 (Not at all confident) $2 \quad 2 \quad 3 \quad 4 \quad 4 \quad 5 \quad 6 \quad 6 \quad 7$ (Completely Confident) 


\section{APPENDIX E: TRIAL TRANSCRIPT}

\section{Jury Instructions}

Presumption of Innocence Defined:

[1] Every person charged with an offence is presumed to be innocent, unless and until the Crown has proved his/her guilt beyond a reasonable doubt.

[2] The indictment tells you and Benjamin Smith what offence the Crown alleges against Benjamin Smith. The charge is not evidence. It is not proof of guilt.

[3] The presumption of innocence lasts throughout the trial. This presumption only ceases to apply if, at the end of the case and on the whole of the evidence, the Crown has proved beyond a reasonable doubt that Benjamin Smith is guilty of the crime charged.

\section{Burden of Proof Defined:}

[1] The person charged does not have to present evidence or prove anything in this case, in particular, that he/she is innocent of the offence charged.

[2] From start to finish, it is the Crown who must prove the guilt of Benjamin Smith beyond a reasonable doubt. You must find Benjamin Smith not guilty of the offence unless the Crown proves beyond a reasonable doubt that he is guilty of it.

\section{Background Information}

Alleged Crime: Assault and Robbery

Victims: John and Louise Bradshaw

Ottawa, Ontario 
Defendant: Benjamin Smith

Ottawa, Ontario

D.O.B.: July $12^{\text {th }}, 1985$

Arrested: June $16^{\text {th }}, 2009$

Crown Opening Statement: The Crown will prove that Benjamin Smith attacked John and Louise Bradshaw while they were walking on $4^{\text {th }}$ Avenue. Mr. Smith confronted the couple, demanding their money and jewellery. Even though the victims willingly gave him their possessions, Mr. Smith physically assaulted John Bradshaw. The Crown will provide a witness that places Benjamin Smith at the scene of the crime, show that he was in possession of the Bradshaw's' stolen goods, and demonstrate that he had both motive and opportunity to commit the crime. In short, we will prove beyond any reasonable doubt that Benjamin Smith is guilty of this crime.

Defence's Opening Statement: The Crown is going to tell you a wonderful tale during this trial. They are going to try to piece together some loose bits of evidence, fill in the gaps with a couple of coincidences, and try to glue it all together with some pretty slippery arguments to convince you that my client is a criminal. The problem with the Crown's story is that my client is not the villain in this tale. The Defence will show that the pieces of evidence don't fit together, that the gaps are too big to be filled with mere coincidences and that the Crown's speculative arguments cannot hold it all together. Benjamin Smith is an innocent man, and you, the jury, will be the real villains if you send this innocent man to jail.

\section{Crown Witness, John Bradshaw}

Crown: What did you and your wife do on the night of June 8, 2009? 
Bradshaw: We had dinner at Von's Bistro.

Crown: What happened to you after dinner?

Bradshaw: We were walking down $4^{\text {th }}$ Avenue to get our car when a man wearing a ski mask jumped out from an alleyway. He demanded my watch and wallet. He also wanted my wife's jewellery and purse.

Crown: What did you do?

Bradshaw: We gave him what he wanted without protesting. Neither of us had very much cash, but my wife was carrying her camera in her purse.

Crown: Then what happened?

Bradshaw: Even though we gave him exactly what he asked for, the man attacked me. He punched my eye, then hit me across the mouth. When I fell to the ground, he ran away. I ended up with a black eye and a cut lip.

\section{Crown Witness, Officer Robert McGrey}

Crown: What did you discover in your investigation of the crime scene?

McGrey: A trail of muddy footprints went from the alleyway to the crime scene.

Apparently, the criminal had walked through a muddy patch before attacking the Bradshaws.

Crown: What did you determine about these footprints?

McGrey: Casts revealed that they were made by a size ten men's Adidas running shoe.

Crown: How did you continue your investigation?

McGrey: I interviewed residents of the loft apartments on $4^{\text {th }}$ Avenue to determine if anyone had seen any suspicious behaviour on the night of the assault. Bernice Durbin, who lives across the street from the crime scene, remembered seeing Benjamin Smith go into the same alleyway from which the Bradshaws' assailant emerged. In addition, we suspect that Benjamin Smith had met with a known seller of stolen goods, Jimmy Logan. I went to Mr. 
Smith's apartment to ask him some questions. He allowed me to come in, answered my questions, and let me look around. I found a pair of muddy shoes and a camera that matched the description of the one stolen from Mrs. Bradshaw. We ran the serial number and found that it was indeed the same camera. I brought Mr. Smith in for further questioning, and he was arrested for assault and robbery one week later.

\section{Defence Cross-Examination:}

Defence: Size ten is a pretty average size for a man's shoe and probably fits thousands of men who live in this city. On top of that, Adidas is one of the most popular brands of running shoes. Is there any laboratory evidence that connects Mr. Smith's Adidas shoes to the footprints at the crime scene?

McGrey: No, there is not.

Defence: Mr. Smith wore a common shoe in a common size and happened to have mud on them after three days of rain. Sounds like you could have walked into thousands of apartments in the city and found the same "evidence."

McGrey: Well, the treadmark from the shoe is identical.

Defence: I see. Now let's review your theory - you believe that Benjamin Smith attacked the Bradshaws and stole several items from them. He then gave the stolen jewellery to Jimmy Logan to sell. Is this your theory?

McGrey: Yes, and I'm still convinced that is what happened.

Defence: In your investigation, did you find any evidence that Jimmy Logan had ever come into possession of the items stolen from the Bradshaws?

McGrey: No, we did not.

Defence: And did you find any evidence that Benjamin Smith had received a large amount of cash that would suggest he had sold the stolen jewellery? 
McGrey: No, we did not. But Logan's stolen goods operation is very sophisticated, and it would be difficult to obtain that kind of evidence.

Defence: So your theory is just a theory.

\section{Crown Witness, Bernice Durbin}

Crown: Did you see anyone near the alleyway on $4^{\text {th }}$ Avenue on the night of the crime?

Durbin: I was looking out of my window that night. I saw this man walking slowly down the street. He turned and walked into the alleyway. The streetlight was out, so I guess he couldn't see me. The man was Benjamin Smith from around the neighbourhood, so I just assumed he was cutting over to the next block. I didn't think about it again until the police interviewed me.

\section{Defence Cross-Examination:}

Defence: Ms. Durbin, you claim that the streetlight was out. If that's true, how could you identify the man walking into the alleyway?

Durbin: It was not very bright out there, but I could still see people on the street.

Defence: Not very bright outside, huh? That doesn't sound like ideal viewing conditions, Ms. Durbin. Now you said that you told the police who you thought the man was -- sounds like you were not quite sure.

Durbin: Well, the man on the street had the same build and everything as Mr. Smith, and I've seen Mr. Smith around the neighbourhood, so that's who I thought it was. I told the police that, and they found out everything that linked him to the crime.

Defence: So essentially you saw a man late at night across a dark street who reminded you of Mr. Smith, so you assumed it was my client. 


\section{Defence's Witness, Benjamin Smith}

Defence: What did you do on the night of June 8,2009 ?

Smith: I ate dinner, went jogging, then watched television.

Defence: Do you often jog at night?

Smith: I probably jog 3 or 4 nights per week. I like to jog at night because it is cooler and quieter.

[Note: There will be 4 different versions of the transcript, each with only one of the following conditions]

(1) I like to jog at night because it is cooler and quieter.

(2) I like to jog at night because it is cooler and quieter. It helps to calm me down, and my psychiatrist recommended it to help me deal with my depression.

(3) I like to jog at night because it is cooler and quieter. It helps to calm me down, and my psychiatrist recommended it to help me deal with my obsessive/compulsive disorder.

(4) I like to jog at night because it is cooler and quieter. It helps to calm me down, and my psychiatrist recommended it to help me deal with my schizophrenia.

Defence: On the night of the crime, did you happen to cross through any mud while you $\operatorname{ran} ?$

Smith: Yeah, it had been raining for the past three days. There was mud everywhere.

Defence: So my client follows his usual exercise program and happens to get mud on his shoes. This hardly seems like enough evidence to brand him a criminal.

\section{Crown Cross-Examination:}

Crown: Were you by yourself throughout your activities on the night of the crime?

Smith: Yes, I was.

Crown: Did you see or talk to anyone who can vouch for your whereabouts?

Smith: No, I didn't. 
Crown: So you don't have an alibi for your whereabouts at the time of the Bradshaws' attack -- how convenient. Mr. Smith, how do you account for the stolen camera found in your apartment?

Smith: I was over by the pawnshop earlier that day. I wanted to see what they would give me for some CDs. Outside the door, this guy asked me if I wanted to buy a camera for $\$ 50$. I knew that camera must be worth $\$ 400$ at least, so I figured I could buy it and sell it for at least $\$ 200$. I know it wasn't smart of me to buy it from him, not knowing where he got it and all. When I was arrested, I tried to give a description of him to the police, but they weren't interested.

Crown: Mr. Smith, we ran a credit check on you, and it appears that you have quite a few outstanding bills. Is it safe to say that you are having a great deal of financial difficulty right now?

Smith: Yeah, you could say that. I have some bill collectors after me.

Crown: Are your money problems bad enough that you would attack someone to get some cash?

Smith: No way -- I'm not that desperate.

Crown: Then tell me, how were you planning to get the money?

Smith: I don't know.

Crown: Let me ask you point blank, Mr. Smith. Did you attack the Bradshaws, steal their jewellery and camera, pass the jewellery on to Jimmy Logan for cash, and keep the camera for yourself?

Smith: No way.

Crown: So you say, Mr. Smith. The evidence says something different. 


\section{Defence Re-direct:}

Defence: Benjamin, when Officer McGrey came to your apartment, he didn't have a search warrant, but you still let him in your apartment, answered his questions, and even let him look around. Why did you do that?

Smith: I was just trying to help out. I didn't have any reason not to; I had nothing to hide.

\section{Crown Closing Statement:}

The defendant, Mr. Smith, was in deep financial trouble. He needed cash and admittedly had no way to get it. But there was one way, wasn't there? He hid in an alleyway and robbed a passing couple. What's worse, he didn't stop there - even after Mr. and Mrs. Bradshaw had handed over their valuables as requested, he still ruthlessly assaulted Mr. Bradshaw. He took the jewellery he stole from the Bradshaws and cashed it in with Jimmy Logan, who is a known trafficker in stolen goods. How do we know this? First, the defendant had no alibi for the night of the burglary, and a witness saw Mr. Smith walk into the alleyway at the crime scene. Second, muddy shoes were found in the defendant's home that had the same size and tread as those made by the Bradshaw's assailant. Third, the stolen camera was found in the defendant's home. There is no doubt that this camera was the one taken from the Bradshaws - the serial number is an exact match. Fourth, the defendant was seen conversing with a known seller of stolen goods, Jimmy Logan, the day after the burglary. Can all these be mere coincidences, as the defence would have you believe? No, you and I both know that this goes beyond a series of coincidences, beyond any reasonable doubt -- the defendant, Benjamin Smith, did commit the crime for which he stands accused. 


\section{Defence's Closing Statement:}

Benjamin Smith thought it was his lucky day. He got a camera cheap from some guy who didn't know what it was worth. Benjamin was going to turn around and resell it for a quick profit. Before he could, the cops came by to ask some questions, and they found him with what turns out to be a stolen camera. That, ladies and gentlemen, is the only evidence that links my client to the Bradshaw's attack. But does that mean he committed the burglary, or that he was just stupid enough to buy something that turned out to be stolen? I have to ask myself, if he stole all that other stuff, why didn't the police find it? And if he already stole that other stuff, where's the money? There simply is no credible evidence to demonstrate that my client committed this crime. The muddy tennis shoes from hundreds of men in that area of town could have fit the footprint casts the police made. The so-called eyewitness saw someone late at night on a dark street who reminded her of Benjamin Smith, so that's who she said it was. If my client really had been guilty, would he have let the police into his home and allowed them to search it without a search warrant? Come on, folks, the Crown is trying to piece together a puzzle, and they don't have enough pieces. Without all those pieces, you must find there's plenty of room for doubt and return a verdict of not guilty.

\section{Crown Rebuttal:}

Criminals sometimes think they are smarter than the rest of us. But if that was true, they would not commit the crime in the first place. So just because a defendant let the police look around his house doesn't mean that he didn't commit the crime. Maybe he thought that just one camera out of a bunch of stolen loot wouldn't give him away. Maybe he didn't know that cameras have serial numbers, too. Maybe he thought he had hidden it too well for them to find. Nobody said that criminals were smart. We have demonstrated that the defendant had motive and opportunity to commit the crime. The Defence never challenged 
that. We found a witness who saw the defendant at the crime scene, and all the Defence could do is try to make you doubt what the witness said. We then offered physical evidence by way of a stolen camera and muddy shoes matching the footprints at the crime scene. The Defence spins some fantasy about how this could have happened, but offers no evidence for their story. The Defence would like you to believe that anything short of a videotape of the defendant attacking the Bradshaws is insufficient evidence. Well, folks, that is not true. You can send that message to the defence by finding the defendant, Benjamin Smith, guilty. 


\section{APPENDIX F: JUROR QUESTIONNAIRE}

\section{Verdict - Robbery Charge}

Robbery Indictment Defined:

343. Every one commits robbery who

(a) steals, and for the purpose of extorting whatever is stolen or to prevent or overcome resistance to the stealing, uses violence or threats of violence to a person or property;

(b) steals from any person and, at the time he steals or immediately before or immediately thereafter, wounds, beats, strikes or uses any personal violence to that person;

(c) assaults any person with intent to steal from him; or

(d) steals from any person while armed with an offensive weapon or imitation thereof.

You will now answer a number of questions about what you have read in the trial transcript. Please answer these questions honestly and to the best of your ability. We ask that you do not turn back to earlier pages after you have completed them.

INSTRUCTIONS: Please respond to the following items with regards to the robbery charge against the defendant.

1. How do you find the defendant, Benjamin Smith?

GUILTY
NOT GUILTY

2. How confident do you feel in your verdict?

$\begin{array}{lllllllllll}0 & 1 & 2 & 3 & 4 & 5 & 6 & 7 & 8 & 9 & 10\end{array}$

Not at all

Confident
Somewhat

Confident
Very Confident 
3. On a scale of 0 to 100 , how guilty do you perceive the defendant to be?

4. Sentencing guidelines states that every person who commits robbery is guilty of an indictable offence and can be punished with imprisonment up to a life sentence.

a) Following these guidelines, if you selected guilty in the first question, what (if any) punishment do you believe the defendant deserves?

(check only one)

no punishment _ imprisonment

b) If you selected imprisonment, please enter a number of years: years

c) Now, ignoring the guidelines, what recommendations would you make regarding the sentencing of the defendant? 
The next set of questions will address specific evidence presented at the trial.

5. Consider the following questions regarding the muddy Adidas running shoes found in Benjamin Smith's apartment:

a. How compelling was this evidence?
1
23
4
5
6
7
8
9

Not at all

Somewhat

Very

compelling

compelling

compelling

b. To what extent do you feel that this evidence suggests that Benjamin Smith is guilty?

$\begin{array}{lllllllll}1 & 2 & 3 & 4 & 5 & 6 & 7 & 8 & 9\end{array}$

Not at all

Somewhat

Very much

c. To what extent did this evidence influence your verdict?

$\begin{array}{lllllllll}1 & 2 & 3 & 4 & 5 & 6 & 7 & 8 & 9\end{array}$

Not at all

Somewhat

Very much

6. Consider the following questions with regards to the stolen camera found in Benjamin Smith's apartment:

a. How compelling was this evidence?
1
23
4
5
$\begin{array}{ll}6 & 7\end{array}$
8
9

Not at all

Somewhat

Very

compelling

compelling

compelling 
b. To what extent do you feel that this evidence suggests that Benjamin Smith is guilty?

$\begin{array}{lllllllll}1 & 2 & 3 & 4 & 5 & 6 & 7 & 8 & 9\end{array}$

Not at all

Somewhat

Very much

c. To what extent did this evidence influence your verdict?

1

2

3

Not at all
4

5

Somewhat
$6 \quad 7$

8

9

Very much 
The next set of questions will address specific people who testified at the trial.

7. To what extent did the victim, John Bradshaw:

Not at all

Very Much

Provide honest testimony

Provide a fair/unbiased testimony

Deliberately omit facts

Exaggerate or sugarcoat the truth

123

$\begin{array}{lllllllll}1 & 2 & 3 & 4 & 5 & 6 & 7 & 8 & 9\end{array}$

$\begin{array}{lllllllll}1 & 2 & 3 & 4 & 5 & 6 & 7 & 8 & 9\end{array}$

$\begin{array}{lllllllll}1 & 2 & 3 & 4 & 5 & 6 & 7 & 8 & 9\end{array}$

8. To what extent did the police officer, Officer Victor McGrey:

Not at all

Somewhat
Very Much

Provide honest testimony

Provide a fair/unbiased picture of

Benjamin Smith

Deliberately omit facts

Exaggerate or sugarcoat the truth $\begin{array}{lllllllll}1 & 2 & 3 & 4 & 5 & 6 & 7 & 8 & 9\end{array}$

$\begin{array}{lllllllll}1 & 2 & 3 & 4 & 5 & 6 & 7 & 8 & 9\end{array}$

$\begin{array}{lllllllll}1 & 2 & 3 & 4 & 5 & 6 & 7 & 8 & 9\end{array}$

$\begin{array}{lllllllll}1 & 2 & 3 & 4 & 5 & 6 & 7 & 8 & 9\end{array}$


9. To what extent did the witness, Bernice Durbin:

Not at all Somewhat

Very Much

Provide honest testimony

$\begin{array}{lllllllll}1 & 2 & 3 & 4 & 5 & 6 & 7 & 8 & 9\end{array}$

Provide an accurate testimony

$\begin{array}{lllllllll}1 & 2 & 3 & 4 & 5 & 6 & 7 & 8 & 9\end{array}$

Deliberately omit facts

$\begin{array}{lllllllll}1 & 2 & 3 & 4 & 5 & 6 & 7 & 8 & 9\end{array}$

Exaggerate or sugarcoat the truth

$\begin{array}{lllllllll}1 & 2 & 3 & 4 & 5 & 6 & 7 & 8 & 9\end{array}$

10. To what extent did the defendant, Benjamin Smith:

Not at all

Very Much

Provide honest testimony

Provide a fair/unbiased picture of

himself

Deliberately omit facts

Exaggerate or sugarcoat the truth $\begin{array}{lllllllll}1 & 2 & 3 & 4 & 5 & 6 & 7 & 8 & 9\end{array}$

$\begin{array}{lllllllll}1 & 2 & 3 & 4 & 5 & 6 & 7 & 8 & 9\end{array}$

$\begin{array}{lllllllll}1 & 2 & 3 & 4 & 5 & 6 & 7 & 8 & 9\end{array}$

$\begin{array}{lllllllll}1 & 2 & 3 & 4 & 5 & 6 & 7 & 8 & 9\end{array}$


11. Using the following scale, please indicate the extent to which the defendant, Benjamin Smith, is:

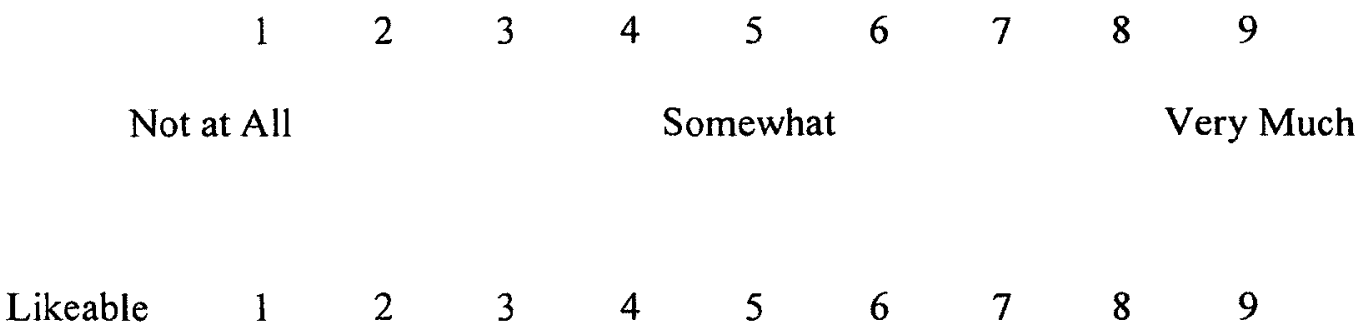

$\begin{array}{llllllllll}\text { Aggressive } & 1 & 2 & 3 & 4 & 5 & 6 & 7 & 8 & 9\end{array}$

$\begin{array}{llllllllll}\text { Kind } & 1 & 2 & 3 & 4 & 5 & 6 & 7 & 8 & 9\end{array}$

$\begin{array}{llllllllll}\text { Intelligent } & 1 & 2 & 3 & 4 & 5 & 6 & 7 & 8 & 9\end{array}$

$\begin{array}{llllllllll}\text { Dishonest } & 1 & 2 & 3 & 4 & 5 & 6 & 7 & 8 & 9\end{array}$

$\begin{array}{llllllllll}\text { Reliable } & 1 & 2 & 3 & 4 & 5 & 6 & 7 & 8 & 9\end{array}$

$\begin{array}{llllllllll}\text { Antagonistic } & 1 & 2 & 3 & 4 & 5 & 6 & 7 & 8 & 9\end{array}$

$\begin{array}{llllllllll}\text { Caring } & 1 & 2 & 3 & 4 & 5 & 6 & 7 & 8 & 9\end{array}$

$\begin{array}{llllllllll}\text { Unfriendly } & 1 & 2 & 3 & 4 & 5 & 6 & 7 & 8 & 9\end{array}$

$\begin{array}{llllllllll}\text { Hardworking } & 1 & 2 & 3 & 4 & 5 & 6 & 7 & 8 & 9\end{array}$

$\begin{array}{llllllllll}\text { Trustworthy } & 1 & 2 & 3 & 4 & 5 & 6 & 7 & 8 & 9\end{array}$ 
JUROR STIGMA TOWARDS MENTAL ILLNESS

$\begin{array}{llllllllll}\text { Responsible } & 1 & 2 & 3 & 4 & 5 & 6 & 7 & 8 & 9\end{array}$

$\begin{array}{llllllllll}\text { Cruel } & 1 & 2 & 3 & 4 & 5 & 6 & 7 & 8 & 9\end{array}$


12. What mental illness did the defendant, Benjamin Smith, have?

No Mental Illness

Depression

Schizophrenia

Obsessive/Compulsive Disorder

13. During the crime what happened to Mr. Bradshaw?

He was punched in the mouth and eye

He was stabbed

His arm was broken

14. During the crime what item was stolen from the Bradshaws?

Shoes

Watch

Cell Phone

Camera 
15. What did the defendant, Benjamin Smith, say he was doing on the night of the crime?

Working

Watching television

Jogging

Running errands

16. Where did the defendant, Benjamin Smith, say he got the camera found in his apartment?

He bought it at an electronics store

He got it from a man outside of a pawn shop

He received it as a gift

He was borrowing it from a friend 
Please answer the following questions by circling your answer choice, where $1=$ strongly disagree, and $5=$ strongly agree.

17. I believe a person with mental illness is a danger to others

1

2
3

Strongly Disagree
4

5

18. I believe a person with mental illness is unpredictable

1

2

Strongly Disagree
3
4

Strongly Agree

19. I believe a person with mental illness is hard to talk with

1

2

Strongly Disagree
Strongly Agree 
21. I believe a person with mental illness would improve if given treatment and support
1
2
3
4
5

Strongly Disagree

Strongly Agree

22. I believe a person with mental illness feels the way we all do at times

1

2

Strongly Disagree
3

4

Strongly Agree

23. I believe a person with mental illness could pull himself/herself together if he/she wanted
1
2
3
4
5

Strongly Disagree

Strongly Agree

24. I believe a person with mental illness can eventually recover

1

2

3

Strongly Disagree
4

5

Strongly Agree

25. I believe a person with mental illness can be as successful at work as others

1

2

Strongly Disagree
3

4

5

Strongly Agree 
26. Treatment can help people with mental illness lead normal lives

1 2

Strongly Disagree
3

4 5

Strongly Agree

27. People are generally caring and sympathetic to people with mental illness

1

2

Strongly Disagree
3

4

5

Strongly Agree 


\section{Demographics}

Finally, we would like to ask you a few questions about yourself.

28. What is your age?

29. What is your gender?

Male

Female

Trans

None of these options are applicable. Please elaborate here:

30. What is your racial/ethnic background?

Asian

Black/African-Canadian

Middle Eastern

East Indian

Hispanic/Latino

White/Caucasian

Aboriginal Canadian/Native Canadian/First Nations

None of these options are applicable. Please elaborate here: 
31. Which of the following statements best describes you?

My grandparents were born and raised in Canada.

My grandparents immigrated to Canada from

My parents immigrated to Canada from

I came to Canada from

32. What is your religion?

33. Do you have a mental illness?

No

Yes

34. Do you know someone who has a mental illness?

No

Yes $\rightarrow$ Please indicate your relationship to this individual: 


\section{APPENDIX G: DEBRIEFING}

\section{Carleton \\ U NIVERSITY}

\section{Study Debriefing for: An Analysis of Juror Decision-Making in a Criminal Trial}

\section{Background Information}

According to the Canadian Charter of Rights and Freedoms, all persons are to be presumed innocent until proven guilty by law in a fair and public hearing by an independent and impartial tribunal (Charter, 1992). Jurors are supposed to be able to make their decision without sympathy, prejudice or fear; and should not be influenced by public opinion. It should be noted that dangerousness and unpredictability are some of the main conceptions about mentally ill people, and it is likely that jurors may have difficulty being impartial in a case involving an accused who has a mental illness.

The media often provide an inaccurate image of mental illness. In an overview of international studies on the portrayal of mental health and illness in the media, Francis et al. (2001) draw this conclusion by stating that mental illness is portrayed negatively, as the media promote negative images and stereotypes. In addition, there is a strong link between mental illness and violence in media messages, and stories associating mental illness with violence and crime were given greater prominence than positive items about mental illness (Francis et al., 2001). These finding highlight the risk of juror bias in cases involving mental illness, and stress the importance of exploring this issue further.

It is essential to distinguish a guilty verdict based on the evidence provided in court, versus a biased verdict based on prejudice. There are a variety of topics which may prompt 
prejudiced attitudes from jurors (i.e., depression/anxiety, and schizophrenia). Studies have highlighted findings demonstrating stereotypes: a mentally ill person is dangerous and violent (Dietrich et al...); alcohol dependent persons are unpredictable and dangerous (Schomerus et al., 2010); schizophrenia evokes a label of dangerousness (Angermeyer et al. 2004). These examples reinforce the idea that this is an area that needs to be addressed in court procedures.

Currently in Canadian courts, there are questions addressing whether a potential juror has watched news reports about the case, or if he or she has a prejudice against a racial group. These kinds of questions allow for courts to attempt the exclusion of racially biased jurors. To date, however, there has not been any exploration about the potential need for a question regarding stigma towards a defendant with a mental illness.

Schuller et al.'s study (2009), involving racial biases in court, assessed the effect of different pre-trial questioning strategies on bias. For example, a single closed-ended question: "Would your ability to judge the evidence in this case without bias, prejudice or partiality be affected by the fact that the person charged is Black?" (Schuller et al., 2009). In comparison, a reflective question instructs participants to consider how bias can influence their judgements, thereby orienting them more toward the process of correction rather than a simple denial of prejudice. Drawing from this research, our current study aims to explore the impact of different types of questioning in terms of reducing stigma towards mentally ill defendants.

\section{Aim of the Study}

The present study was designed to examine the potential prejudicial impact of mental illness on the choices made by Canadian mock jurors. More specifically, it aims to explore the effects of different types of questioning on stigma and decision-making. Consequently, 
this study aims to answer four research questions: First, do mock juror's attitude ratings indicate stigma towards mental illness, and is this demonstrated in juror verdicts? Second, are certain mental illnesses more likely to be stigmatized than others? Third, how does questioning affect decision-making? Fourth, can stigma be reduced via questioning in order to ensure impartiality?

\section{True Nature of the Study}

As you can see, the purpose of this study is more than just examining mock jurors' decision-making in an armed-robbery case, as was stated in the consent form. Rather, the ultimate purpose of this research is to examine any harmful effects that may arise due to the manipulation of the defendant's mental illness (i.e. no mental illness, depression, obsessive compulsive disorder, and schizophrenia). However, because there is a risk for social desirability bias [which is defined as bias that results from participants providing responses that make them look good rather than responses that are honest], it was decided that words associated with prejudice, stigma, bias, and mental illness would be left out of any materials presented before the study began. In light of the true nature of this study, if you experience any distress as a result of your participation or have any concerns, I encourage you to contact either myself, Dr. Maeder, Dr. Anne Bowker, or Monique Sénéchal (see contact information provided on page 3 ).

\section{Implications}

Assessing stigma and prejudice towards a defendant is crucial in ensuring the defendant's right to a fair trial. Using the stigma ratings in conjunction with questioning procedures, we hope to identify whether stigma towards mental illness is of great concern in legal settings, and to explore procedures to reduce bias and encourage fairness. Juror bias 
may interfere with the Canadian standards of rights and freedoms, and thus the different questioning formats are important in investigating the process of stigma and in suggesting key avenues and strategies to address these issues. Findings from this study have the potential for significant implications in legal proceedings and policies, i.e. the introduction and implementation of a mental-illness questioning into judicial guidelines and procedures.

I sincerely appreciate your participation in this study. I would like to reassure you, once again, that all answers will be kept anonymous, and confidential. As was noted above and in the informed consent process, if you experience any distress as a result of your participation in this study, please feel free to contact Counselling Services:

Carleton University Health and Counselling Services

Carleton Technology \& Training Centre, Room 2600

In-Clinic Counselling Hours: Monday - Friday, 8:30am-4:30pm (September - April) http://www2.carleton.ca/health/counselling-services/

Phone: (613)520-6674

If you have any ethical concerns about the way you have been treated as a participant, please contact or Monique Sénéchal, the Chair of the Psychology Research Ethics Board, at Ext. 1155, monique_senechal@carleton.ca. For other general concerns please contact Dr. Anne Bowker, Chair of Department of Psychology, Carleton University, at 613-520-2600 ext. 8218, anne bowker@carleton.ca.

If you have any questions or concerns about this study, please feel free to contact:

Annik Mossière
Carleton University
Psychology Department
amossier@.connect.carleton.ca

Annik Mossière

Carleton University amossier@connect.carleton.ca

\author{
Dr. Evelyn Maeder \\ Carleton University \\ Psychology \& Criminology Departments \\ (613) $520-2600 \times 2421$
}

Evelyn_Maeder@carleton.ca

\section{Thank You!}




\section{REFERENCES}

Angermeyer, M.C., Buyantugs, L., Kenzine, D.V., Matschinger, H. (2004). Effects of labelling on public attitudes towards people with schizophrenia: are there cultural differences? Acta Psychiatr Scand, 109, 420-425.

Canadian Charter of Rights and Freedoms, PART I OF THE CONSTITUTION ACT, 1982

Crocker, C.B., \& Kovera, M.B. (2010). The effects of rehabilitative voir dire on juror bias and decision making. Law and Human Behaviour, 34, 212-226.

CSC launches a comprehensive mental health strategy. Correctional Service Canada: Let's Talk, Vol 34(1). Retrieved January $4^{\text {th }}, 2011$, from: http://www.csc-scc.gc.ca/text/pblct/lt-en/2007/32-1/2eng.shtml

Dietrich, S., Herider, D., Matschinger, H., Angermeyer, M.C (2006). Influence of newspaper reporting on adolescents' attitudes toward people with mental illness. Social Psychiatry and Psychiatric Epidemiology, 41, 318-322

Francis, C., Pirkis, J., Dunt, D., Blood, R.W. (2001). Mental health and illness in the media: A review of the literature. Commonwealth Department of Health and Ageing Canberra.

Koskie, J., Hendrick, K., \& Kelly, D. (2010). The substandard treatment of mentally ill inmates is criminal: experts. Canadian Mental Health Association. News Release, November $4^{\text {th }}, 2010$. Retrieved on December $6^{\text {th }}, 2010$, from: http://www.cmha.ca/bins/content page.asp?cid=6-20-21-965-773

Schomerus, G., Holzinger, A., Matschinger, H., Lucht, M., \& Angermeyer, M. (2010). Public attitudes towards alcohol dependence an overview. Psychiatrische Praxis, 37, 111-118.

Schuller, R., Kazoleas, V., Kawakami, K. (2009). The impact of prejudice screening procedures on racial bias in the courtroom. Law \& Human Behaviour, 33, 320-328. 


\section{Informed Consent to the Use of Data}

The purpose of an informed consent is to ensure that you now understand the true purpose of the study and that you agree to allow your data to be used for research and teaching purposes.

Because you were only told of the procedures and not the true purpose of this study at the beginning, we are now asking for your consent to allow your data to be used for research and teaching purposes.

Purpose. The purpose of this study is to assess whether there is juror stigma towards mental illness, and what impact challenge for cause procedures have in such cases.

Anonymity/Confidentiality. The data collected in this study are kept anonymous and

confidential. The consent forms are kept separate from your responses.

Right to withdraw data. You have the right to indicate that you do not wish your data to be used in this study. If you indicate this is your choice, then all measures you have provided will be destroyed, however you will still receive credit for your participation.

I have read the above description of the study investigating juror stigma towards mental illness, and the impact of challenge for cause procedures. The data in the study will be used in research publications or for teaching purposes

I have read the above form and now understand the true nature of the study. By checking this box, I'm indicating that I agree to allow the data I have provided to be used for these purposes.

I have read the above form and now understand the true nature of the study. By checking this box, I'm indicating that I disagree to allow the data I have provided to be used for these purposes. 